\title{
The Effect of Within-Sector, Upstream and Downstream Environmental Taxes on Innovation and Productivity*
}

\author{
Chiara Franco $^{\dagger} \quad$ Giovanni Marin ${ }^{\ddagger}$
}

\begin{abstract}
The aim of this paper is to investigate the effect of environmental regulatory stringency on innovation and productivity using a panel of 8 European countries for 13 manufacturing sectors over the years 2001-2007. This research topic falls under the heading of the Porter Hypothesis (PH) of which different versions have been tested. We consider both the strong and the weak versions of the $\mathrm{PH}$, while also adding some peculiar features to the analysis. Firstly, we assess the role played by environmental taxes, that is an instrument rarely tested as a factor which can support the PH. Secondly, we analyse not only the effect of environmental taxes within a given sector (within-sector), but also the role played by environmental taxes in upstream and downstream sectors in terms of input-output relationships. Thirdly, we test these relationships also 'indirectly' by verifying whether innovation is one of the channels through which higher sectoral productivity can be achieved by imposing tighter environmental regulations.

Our main findings suggest that downstream stringency is the most relevant driver of innovation and productivity while within-sector regulations only affect productivity but not innovation. Moreover, the effect of regulations on productivity is mostly direct, while the part of the effect mediated by induced innovations, as measured by patents, is relevant only for what concerns downstream regulations.
\end{abstract}

Keywords: Downstream, Upstream, Environmental Taxes, Input-Output, Porter Hypothesis. JEL: L6, O13, Q55

${ }^{*}$ Chiara Franco acknowledges the financial support of the National Research Project PRIN-MIUR 2010-2011 'Climate Changes in the Mediterranean Area: Evolutionary Scenarios, Mitigation Policies and Technological Innovation'. Giovanni Marin acknowledges the financial support of the EMInInn research project, funded by the European Union under the 7 th Framework Programme for Research (Grant Agreement No. 283002, www.emininn.eu). We thank the participants to the Workshop on 'Eco Innovation in the EU - Conceptual and Empirical Perspectives' (University of Ferrara, Italy, September 2013) and to the 13th EACES (European Association of Comparative Economic Studies) Biennial Conference (Budapest, Hungary, September 2014). We would like to thank two anonymous referees for their suggestions and comments. Usual disclaimer applies.

${ }^{\dagger}$ Catholic University of the Sacred Heart of Milan, Italy; SEEDS Sustainability Environmental Economics and Dynamics Studies, Ferrara, Italy. E-mail: chiara.franco@unicatt.it.

${ }^{\ddagger}$ IRCrES-CNR, Research Institute on Sustainable Economic Growth, National Research Council of Italy, Via Bassini, 15, 20133 Milano, Italy; OFCE-SciencesPo, Sophia Antipolis, France; SEEDS Sustainability Environmental Economics and Dynamics Studies, Ferrara, Italy. E-mail: giovanni.marin@ircres.cnr.it. 


\section{Introduction}

The studies which have the assessment of the so called 'Porter Hypothesis' (PH) (Porter and van der Linde, 1995) as a main research question concentrate on trying to explain whether more stringent environmental regulations can influence the economic performance of firms, sectors or countries. One of the theoretical streams of this literature suggests the idea that environmental protection can generate extra costs for firms, therefore causing their domestic and international competitiveness to be negatively affected. This means that, when firms have to comply with environmental regulations, they can incur higher operating costs which may lead to a decrease in productive investments, measured productivity and profit margins. On the contrary, in the Porter's idea (Porter, 1991; Porter and van der Linde, 1995), reducing the waste of resources associated with pollution can trigger virtuous mechanisms thus offsetting additional costs. The final result is that firms can improve their performance and competitiveness. Within this framework, environmental regulation can point to inefficiencies in the usage of resources, creating the right conditions for regulated actors to take full advantage of being first movers (once the regulations are adopted by their competitors), or force firms to change their inefficient routines.

From an empirical point of view, different versions of the $\mathrm{PH}$ have been tested. Jaffe and Palmer (1997) distinguish among three different versions of the PH, namely the 'narrow', the 'weak' and the 'strong'. The narrow version is based on the idea that only certain types of environmental regulations such as market-based (flexible) environmental regulations (e.g. tradable permits or Pigouvian taxes), and, in general, those focusing on outcomes rather than on processes - can stimulate innovation activities and overall economic performance. Instead, the weak version argues that all types of environmental regulations can involve mechanisms leading firms to maximise profits subject to further constraints introduced by regulations themselves. This could lead to higher innovation rate, with no a priori expectations about the net effect on productivity. Finally, the strong version of the PH implies that environmental regulations, either market-based or standard-based, can lead to improved competitiveness and productivity through innovations induced by regulations, consequently allowing firms to more than compensate for compliance costs. Empirical studies fail to reach unanimous conclusions on whether these effects are actually at work. Therefore, in this paper, we delve deeper into this issue by providing empirical evidence on the role played by environmental taxes for the $\mathrm{PH}$ to occur. We focus on the manufacturing sectors of 8 European countries over the 2001-2007 period.

Our contribution to the literature is threefold. Firstly, with the exception of the paper by Leiter et al. (2011), environmental taxes have hardly ever been investigated as types of regulations potentially linked to the PH. Indeed, according to Porter's idea, market-based instruments are more likely to cause the PH to occur than command-and-control instruments. Secondly, whereas most of the previous analyses only focus on the effects generated by environmental stringency in the same sector (Kneller and Manderson, 2012), we add to the analysis the study of the inter-industry effects of stringency measures. In order to carry out this empirical exercise we make use of annual input-output data. Thirdly, we examine the effects not only by considering direct relationships (i.e. from taxes to innovation or productivity) but also trying to determine whether innovation activities are among the indirect channels through which the effects of environmental taxes on productivity can become evident.

Our main findings suggest that both the weak and the strong version of the PH are confirmed, since our measures of environmental regulatory stringency are positively related to both innovation (induced innovation - weak version of the $\mathrm{PH}$ ) and productivity (strong version of the $\mathrm{PH}$ ). The strongest effect appears to be related to downstream regulatory stringency. Conversely, the effect generated by the upstream regulatory stringency yields negative results, especially when testing the strong $\mathrm{PH}$, while within-sector regulatory stringency does not affect innovation but only stimulates productivity. Moreover, by making use of the IV approach to correct for the endogeneity of patents in the productivity equation (Lanoie et al., 2011), we are able to investigate the role of innovation as a mediating factor possibly leading sectors to more than offset regulation costs.

The paper is organised as follows. Section 2 provides the theoretical framework, by reviewing theoretical and empirical evidence on the $\mathrm{PH}$ and by stressing the importance of intersectoral linkages. Section 3 discusses the empirical approach, while section 4 describes the data used. Section 5 presents the results and, lastly, section 6 offers some conclusions.

\section{Theoretical framework}

The idea of the PH falls within the stream of literature investigating the link between environmental regulation and competitiveness at different levels of analysis (countries, sectors or firms). In their review 
of the literature, Iraldo et al. (2011) point out that the heterogeneity of environmental policies may result in differentiated effects on competitiveness, and that differences in the reactions across sectors should also be taken into account.

In the original formulation by Porter (1991) and Porter and van der Linde (1995), the PH is considered to be verified when more stringent environmental policies do not cause loss of competitiveness and may even improve the productivity and financial performance of regulated entities. The idea is that environmental regulations may positively influence production efficiency and technological improvements. These potential effects may also be due to an increase in the firms' awareness about more environmentallyfriendly ways to handle their production process. The missing aspect disregarded in the analysis is that environmental regulatory policy does not merely exert 'performance' pressures on firms belonging to the targeted sector, but they also affect those firms which are connected to the regulated firms through value chain relationships such as customer-supplier relationships.

The debate developed around the $\mathrm{PH}$ has not yet reached any clear-cut conclusions. This seems to be true from both a theoretical (Mohr, 2002; Xepapadeas and de Zeeuw, 1999) and from an empirical point of view, since the existing contributions point to different results (see Ambec et al. (2013) for a comprehensive review). According to Leiter et al. (2011), one of the main reasons for which non-homogeneous results have been achieved is that different proxies for environmental regulations have been used. Indeed, pollution abatement costs can generate different effects when compared to environmental taxes. Moreover, as pointed out by Ambec et al. (2013), the PH does not claim that higher compliance costs lead to higher levels of innovation levels but rather that they stimulate investments in new technological knowledge possibly spurring innovation.

Jaffe and Palmer (1997) provide a description of the three different versions of the PH. Firstly, the 'weak' version says that environmental regulations can foster specific types of innovations, as these new constraints affect the profit-maximising behaviour of firms. Indeed, being on the market with such cost constraints may force firms to make some changes at the technological and organisational level with the aim of producing or adopting innovations. As underlined by the authors, this version also implies that, when deciding to introduce an innovation following the implementation of a new the regulation, opportunity costs should be lower than the expected benefits.

From an empirical point of view, even though contrasting results have emerged concerning this aspect, the induced innovation hypothesis (which is closely connected to the 'weak' version of the $\mathrm{PH}$ ) tends to be confirmed, with some exceptions. In this regard, Jaffe and Palmer (1997) offer evidence of a positive relationship, albeit not significant, between pollution abatement costs and innovation rate as measured by patent applications. On the other hand, a positive and significant effect is found for R\&D expenditure. Similar conclusions are reached by other papers, such as the one by Johnstone et al. (2010), which focuses on renewable energy policy measures in 25 countries over the 1978-2003 period, or the study by Popp (2006), which looks at the role played by environmental regulations on sulphur dioxide in the US and nitrogen dioxides in Japan and Germany. Johnstone et al. (2012) carry out an analysis on 77 countries over the years 2001-2007 and find that tighter environmental regulations positively affect environmental innovation. A similar perspective is adopted by those papers examining the effect of environmental regulations on $R \& D$ expenditures or environmental patents, thus following a narrower approach. The point being investigated is whether the innovation generated by new regulations is restricted to environmentally-related patents. For example, the analysis by Brunnermeier and Cohen (2003) acknowledges a positive but limited increase in environmental patents for US manufacturing industries following an increase in the pollution abatement expenditure. Similarly, Kneller and Manderson (2012) study the case of 25 UK manufacturing industries over the 2000-2006 period, looking at how expenditure in pollution control affects innovation measured by environmental R\&D as well as investments in environmental capital. Their findings suggest that what drives the positive effect of environmental regulation on innovation is the crowding out effect of environmental R\&D compared to other types of R\&D investments. The bidirectional linkages between emissions and innovation are examined by CarrionFlores and Innes (2010) who use US sectoral data for the 1989-2004 period. Their main findings suggest a negative relationship in both directions even though the effect on long-term emissions reduction induced by innovation is small.

An attempt to go beyond the usual framework of firms complying with regulation costs is proposed by Ford et al. (2014). They use survey data to analyse the effect of environmental regulatory stringency on Australian gas and oil industries. They recognise that both regulatory and competitive advantages can foster greater innovation (of any type). They also show that the relationship between environmental regulation and innovation can be affected not only by R\&D expenditure but also, for example, by cooperation among firms. 
Secondly, Jaffe and Palmer (1997) point out that the 'strong' version of the PH entails estimating the effects of environmental regulations on the economic performance of firms, sectors or countries. In particular, they underline that firms may not need to follow a profit maximising behaviour and, therefore, both processes and outcomes are affected by environmental regulations. However, empirical results have produced mixed evidence in this case too. Early studies generally did not find evidence of the strong version of the PH (Gollop and Roberts, 1983), but, more recently, a positive effect seems to have been identified, thus supporting this version of the PH. Hamamoto (2006) underlines the positive impact of environmental regulations on the productivity of Japan's manufacturing sectors, caused by positive effects on R\&D. Lanoie et al. (2008) put forward empirical evidence concerning the effect which stringent environmental regulations may have on productivity in 17 Canadian manufacturing industries. ${ }^{1}$ They consider a dynamic model and find that the contemporaneous effect of environmental regulation on productivity is negative, but a positive impact is detected when using lagged environmental regulation variables $^{2}$. However, results emerging from other empirical studies are less robust in this respect. A recent paper by Rexhäuser and Rammer (2014) presents a firm-level study using CIS data for the year 2009. The authors claim that differences in environmental innovations considered, are the main reasons why the empirical results concerning the PH are so controversial. Rubashkina et al. (2015) test both the 'weak' and 'strong' version of the PH for manufacturing sectors in 17 countries over the years 19972009 by using pollution abatement and control expenditure (PACE) as a proxy for regulatory stringency. Their results, which account for the endogeneity of the policy indicator, provide evidence confirming the induced innovation hypothesis ('weak' version of the $\mathrm{PH}$, measured using patents) while no relationship is found between PACE and total factor productivity ('strong' version of the PH). A different empirical approach is followed by Mohnen and Van Leeuwen (2015) who use a structural equation modelling to search for effects of carbon taxes on environment-related investment and on productivity as well. The peculiarity of their analysis lies in the estimation of complementarities between product, process and eco-innovations to understand whether they may have some effect on productivity. The sample is made up of Dutch firms analyzed over the 2000-2008 period. Their results supports the weak version of the PH while the strong version is not confirmed.

Finally, Jaffe and Palmer (1997) also consider a slightly different version of the PH, i.e. the so called 'narrow' version. As Lanoie et al. (2011) point out, in order to effectively test the narrow version of the $\mathrm{PH}$, the innovative effects of flexible policy instruments, such as environmental taxes should be compared with technology based standards, which are usually seen as more prescriptive policies, preventing firms from being completely free to choose the most cost-effective production methods. The authors test this hypothesis and find that increasing innovation results from the implementation of performance standards rather than technology-based standards. Moreover, besides considering the usual direct effect, they also test the mediating effect of innovation on productivity . Their result suggest the existence of a positive effect mediated by R\&D ${ }^{3}$.

\subsection{The role of intersectoral linkages}

All the empirical studies reviewed above share a common feature: they investigate the effects of environmental regulation on innovation, competitiveness and productivity based on the implicit assumption that the inducement effect of environmental regulatory stringency regards only firms, sectors and countries directly targeted by environmental regulations (within-firm/sector/country regulation). This implicit assumption is straightforward when investigating the adoption of innovations. However, it is reasonable to assume that a wider variety of actors are involved in the phase of invention and development of new or improved technologies aimed at responding to environmental regulations. Recent theoretical contributions have stressed the importance of suppliers, in the form of upstream firms and sectors, as a crucial source

\footnotetext{
${ }^{1}$ A potential drawback of these studies, along with the paper by Managi et al. (2005), is that the proxy used to capture environmental regulation is biased towards command-and-control measures.

${ }^{2}$ The effect of environmental regulations has been examined not only in relation to productivity but also considering whether they affect investment decisions. Gray and Shadbegian (1998) and Gray and Shadbegian (2003) find that the investment decisions of US paper mills in less polluting types of production processes can be ascribed to more stringent air and water regulations. However, their study also detects an overall negative effect on productivity due to the fact that investments are diverted from production activities. Leiter et al. (2011) examine how environmental regulations, measured using sectoral environmental taxes, can affect different types of investments such as gross investments in tangible goods, machinery, construction and productive investments. Positive albeit diminishing effects are found in 9 manufacturing industries examined across 21 European countries over the 1998-2007 period.

${ }^{3} \mathrm{~A}$ stream of literature which measures the impact of environmental regulation on competitiveness but without focusing directly on innovation and productivity looks at the effect on exports. In this respect, Costantini and Mazzanti (2012), provide empirical evidence for 15 European countries over the 1996-2007 period and find that the strong version of the PH is verified.
} 
of technology advancements to cope with environmental regulations. These effects have been modelled mainly in theoretical frameworks without empirical applications.

The need to pay attention to intersectoral linkages when looking at the role played by environmental policy was first put forward by Ulph and Valentini (1997) starting from the idea that governments are compelled to homogenise their environmental policies to avoid capital flights. In their model, which is a three-stage game, if firms can move across countries, environmental taxes become a tool to spread the effect of regulation to other sectors. By extending the work by Hoel (1994), they suggest that the location decision of firms can be influenced by both costs and demand effects. Indeed, by assuming the market size - previously seen by Hoel (1994) as exogenous - to be instead endogenous (demand side), the interplay of demand and costs can affect the way in which environmental taxes influence other industries. This is because, although they are not directly affected by a certain tax, these industries are nevertheless linked to the sectors originally targeted by the environmental regulation.

Greaker (2006) builds a two-sector model in which a stringent environmental regulations affects a polluting industry (downstream). This industry downsizes pollution by means of abatement technologies supplied by the pollution abatement service sector (upstream). In this setting, by boosting the demand for pollution abatement equipment, stringent downstream environmental regulations stimulate innovation as well as entry into the pollution abatement sector.

In the same way, Heyes and Kapur (2011) illustrate a very similar model in which both the regulated polluting firm (downstream) and the specialised supplier of the abatement technology (upstream) perform R\&D aimed at obtaining a temporary monopoly (by means of a patent) for the supply of the pollution abatement technology. Even though the objective of their article is to investigate a dynamically optimal level of regulatory stringency, this is the first theoretical contribution explicitly stating that both the polluting firm and the specialised suppliers of pollution abatement technology are stimulated to perform innovation activities.

Perino (2010) presents a theoretical model in which a downstream polluting industry needs to buy abatement technology from an upstream industry characterised by monopolistic power. Even though the paper focuses on comparing taxes (and in particular, emission taxes) with tradable permits, we learn the key lesson that the intesectoral linkages play an important role when considering the diffusion of new technologies. In particular, if the optimum consists in the complete diffusion of the new technology, then environmental taxes are better policy tools than tradable permits in terms of both efficiency and effectiveness.

Remarkably, these recent theoretical contributions about the role of intersectoral linkages in the literature on the $\mathrm{PH}$ have no empirical counterparts. This is precisely the gap which our paper tries to fill. In particular, our approach is innovative because it tests the effect of environmental regulations on a series of indicators of performance by also considering the stringency of the downstream and upstream sectors. This is done through the use of input-output table. An example of the way in which environmental taxes in a given sector can affect other sectors is provided by Sugeta and Matsumoto (2007). In their paper, they consider the case of vertically related markets posing the question of how to design an optimal taxation policy when firms in downstream sectors buy intermediate inputs from upstream firms and they both contribute to the emission of pollutants. The example they provide is particularly relevant and can be applied to our theoretical framework too. The authors explain that upstream taxes are consumption taxes imposed on petroleum products imported by upstream oil companies and used by downstream firms. Instead, downstream taxes are imposed when firms using heavy oil have to pay emission fees.

In our view, if patents mainly cover product innovations, we should expect an increase in the demand for better technologies by downstream sectors towards their suppliers of technologies, for which these new technologies represent product innovations as a consequence of more stringent environmental regulations. Secondly, if the upstream sectors are affected by increasing costs due to regulation, these costs may partially result in higher prices. The extent to which increasing costs result in higher prices and not in lower margins depends on the structure of the specific market for intermediate goods (e.g. market power, differentiation of products, number of customers, elasticity of supply and demand). If the pass-through of costs is relevant, downstream sectors are stimulated to innovate in order to deal with the new relative prices of intermediate goods (induced innovation).

\section{Empirical model}

The purpose of our empirical approach is to verify whether environmental regulatory stringency, measured here through environmental taxes, can influence the rate of innovation and productivity. The peculiarity of our study is that, following Lanoie et al. (2011), we aim to investigate the links between environmental 
regulatory stringency, innovation and productivity within the same framework. We estimate the following benchmark equation:

$$
\text { Outcome }_{c s, t}=\sum_{j} \gamma_{j} \text { Env }_{-} \operatorname{string}_{c s, t-1}^{j}+\sum_{k} \delta_{k} x_{c s, t-1}^{k}+\mu_{c s}+\tau_{t}+\varepsilon_{c s, t}
$$

where:

- Outcome $e_{c s, t}$ is the dependent variable, namely total patents, environmental patents, total factor productivity or value added for country $c$, sector $s$ and time $t$;

- Env_string $g_{c s, t-1}^{j}$ is our set of measures of environmental policy stringency, where $j$ is within-sector, upstream and downstream environmental tax intensity;

- $x_{c s, t-1}^{k}$ is our set of control variables $k$;

- $\mu_{c s}$ are country-sector fixed effects;

- $\tau_{t}$ are year dummies;

- $\varepsilon_{c s, t}$ is the usual error term.

To deal with possible lags in adapting to new regulatory conditions and to avoid issues of reverse causality, our indicators of environmental tax intensity (as well as all our control variables) are included in the regressions with one year lag. Reverse causality issue may occur because, for example, innovation, by (possibly) reducing energy requirements, can contribute to decrease contemporaneous expenditure in energy taxes. Yet, the current innovation output has no effect on the past energy intensity. Moreover, the importance of introducing lagged effects of environmental policy is underlined in other papers such as the one by Broberg et al. (2013).

[Figure 1 about here]

The empirical approach is implemented in two steps as described in Figure 1. First, we investigate the direct link existing between the stringency of environmental regulations (within-sector, upstream and downstream environmental regulations) and patenting (path 1). We then assess the effect of the stringency of environmental regulations on productivity (and value added). By including (instrumented) patenting as an additional covariate in the productivity equation, we can decompose the direct effect of environmental regulation on productivity (path 2) and its indirect (mediated) effect triggered by innovation (path 3).

As highlighted by the literature that looked at the link between regulation and innovation (CarrionFlores and Innes, 2010; Rubashkina et al., 2015), proxies of environmental regulatory stringency such as pollution abatement control expenditure (Rubashkina et al., 2015) or emissions (Carrion-Flores and Innes, 2010) are likely to be endogenous for two possible reasons. Firstly, there could be confounding factors that affect both innovation (and productivity) and the measures of regulatory stringency, leading to an omitted variable bias. Secondly, reverse causality may arise if innovation may help reduce pollution abatement control expenditure (Rubashkina et al., 2015), emissions (Carrion-Flores and Innes, 2010) or, in our case, environmental taxes. For what concerns our measures of environmental regulatory stringency, we argue that reverse causality is not likely to affect our estimates. Differently from emissions and PACE, that are indirect measures of regulatory stringency that already account for behavioural responses (e.g. induced innovation) by regulated agents, environmental tax rates are exogenously set by the government. Moreover, we believe that even though some adaptive response in terms of reduction of the 'tax base' (e.g. energy consumption for energy taxes) is to be expected as a consequence of environmental taxes, the inclusion of the measures of lagged regulatory stringency is likely to reduce this issue. In addition, while reverse causality is potentially an issue for what concerns within-sector environmental tax intensity, little risk of reverse causality is expected for upstream and downstream environmental tax intensity because of the distinction between the sector that innovates and the sectors (upstream and downstream, respectively) that are affected by higher or lower environmental taxes. Finally, for what concerns the issue of omitted variable bias, we control for important drivers of patenting as well as for sector-country specific time invariant characteristics and year-specific shocks.

In addition to that, as discussed in Lanoie et al. (2011), innovation is endogenous in the economic performance equation (i.e. our productivity equation) because innovation and productivity are both 
affected by regulation and they are simultaneously determined. ${ }^{4}$ In a situation in which productivity is a function of regulation, innovation and other factors, and at the same time innovation is also a function, among other factors, of regulation, we would not be able to correctly identify the effect of regulation and innovation on productivity. For this reason, we use an instrumental variables approach as in Lanoie et al. (2011) to correctly identify the effect of innovation (and consequently of regulation) on productivity.

All in all, we want to stress that, despite the use of lagged regulation proxies and of instrumental variables for patents, our regressions provide results that can be seen more as correlations rather than true causal effects due to the uncertainties in the choice of the lag structure (see section 3.2) and possible time-variant confounding factors that may affect both innovation and regulation that are not partialled out by our set of control variables.

\subsection{Direct links between environmental regulations and competitiveness}

In this sub-section we describe our empirical strategy. In all our regressions we consider country-sector fixed effects and year dummies. This is done in order to account for unobservable time invariant countrysector features and for EU-wide unobserved shocks such as, for instance, environmental policies influencing all countries or shocks to international energy prices. As for our set of dependent variables, we first estimate a baseline model without any indicators of environmental stringency, in order to assess the role of our set of control variables. In a second set of specifications, we investigate the effect of withinsector, upstream and downstream environmental stringency separately. After that, we introduce the three measures into the same regression equation. We repeat this exercise firstly using as our dependent variable patent applications (knowledge production function), then TFP and finally value added.

\subsubsection{Knowledge production function}

Path (1) in Figure 1 closely follows the mechanics of the induced innovation effect caused by environmental regulatory stringency as indicated by the weak version of the $\mathrm{PH}$. We investigate this effect within the general framework of a knowledge production function (Griliches, 1979), with total patents as dependent variable. $^{5}$ This specification is in line with the model tested by Jaffe and Palmer (1997), in which innovation is not split into environmentally-related and non environmentally related domains. In order to evaluate the robustness of our results, we illustrate and discuss the results for two different methodologies (i.e. concordance matrices) to assign patents to industries (see section 4.1).

As an additional level of analysis, we investigate the extent to which regulations affect specific kinds of technologies, especially those more strictly linked to improvements of the environmental performance of production and consumption. The first difficulty encountered is to identify with sufficient precision the specific technologies which are more likely to be influenced by more expensive resources or pollution releases due to taxes. Energy efficiency, for example, is a very general and broad concept and it can be pursued by means of a wide range of technological innovations. Moreover, the response to more expensive environmental inputs and pollution releases might go beyond simple improvements in environmental efficiency, with more radical changes to processes and products ${ }^{6}$. To the best of our knowledge, the only work on European countries estimating the effect of environmental regulatory stringency (more specifically, what the authors define as endogenous regulatory stringency) on environmental patents from a sectoral perspective is the paper by Ghisetti and Quatraro (2013) ${ }^{7}$. They use actual patent applications by sector and region based on aggregate firm-level data for Italy (ORBIS database); they then identify environmental patents based on IPC classes. However, the main limitation of this kind of approach when applied to our context, is the incomplete coverage of patents matched by using firm-level data such as those from the ORBIS database. We assign environmental patents to sectors based on a 'static' IPC-NACE concordance (Schmoch et al., 2003; Lybbert and Zolas, 2014) and we identify environmental patents based on a static list of IPC classes. Yet, this method is likely to generate some distortions due

\footnotetext{
${ }^{4}$ Following the seminal work of Crepon et al. (1998), an extensive literature has emphasized the possibility of reverse causality and simultaneity between innovation and productivity. This is one of the reasons motivating the use of IVs for instrumenting patents in our productivity equation. However, the review of this literature goes beyond the aim of this paper.

${ }^{5}$ Many empirical analyses treat patents as a count variable. However, when assigning patents to sectors or countries, the issue of international (or intersectoral) co-patenting patterns implies fractional assignment of patents to countries or sectors. This results in non-integer values for patent counts. Moreover, our measure of total patents is always different from zero for all observations, thus allowing us to take the logarithm without losing any observation.

${ }^{6}$ Organisational changes are also likely to occur due to more stringent environmental regulations. However, patent data do not represent a suitable tool to capture these kinds of responses.

${ }^{7}$ These types of studies have been carried out mostly on the US (e.g. Brunnermeier and Cohen (2003) and Carrion-Flores and Innes (2010) since data on actual patents by sector are more easily available.
} 
to the fact that specific technologies (e.g. environmental technologies identified through IPC classes) are linked a priori to specific sectors (through the static IPC-NACE concordance).

As inputs for the knowledge production function we include the stock of available knowledge (logarithm of patent stock), the average quality of human capital (proxied by the logarithm of average wage), the logarithm of total employees to control for the scale of the sector as well as the share of large firms as a proxy for market structure. Moreover, we include year dummies to account, among other things, for changes in the propensity to patent which are common to all sectors and countries as well as for EU-wide policies which are likely to affect both dependent and independent variables.

Several problems can affect panel data regressions like the one estimated here. As a matter of fact, residuals might be heteroskedastic and autocorrelated and display cross-sectional dependence. Through specific tests ${ }^{8}$, we found all the above problems in our empirical model. These problems are likely to result into biased standard errors. For this reason, we employ the estimators proposed by Hoechle (2007), in which point parameters are estimated with the classical fixed effect (country-sector) model, while standard errors are estimated by means of the Driscoll-Kraay non-parametric procedure (Driscoll and Kraay, 1998) which corrects standard errors to account for all the three problems, namely cross-sectional dependence, autocorrelation and heteroskedasticity. ${ }^{9}$

\subsubsection{Productivity equation}

To test the strong version of the $\mathrm{PH}$, we estimate the direct effect of our measures of environmental stringency on productivity, which is the path (2) in Figure 1, while also accounting for the 'indirect' effect (through path 3 ) by including lagged patents (considered as endogenous) as a control variable. In this case, environmental regulatory stringency can contribute to improving performance beyond the mere effect mediated by patents. We use two different specifications. In the first specification, we use an index of total factor productivity (TFP). In the second specification, we estimate an extended production function in which value added is a function of labour input, investment and innovation output (i.e. patents).

In this part of the analysis, environmental regulation might, for example, stimulate and accelerate (unobserved) organisational changes, with positive effects on productivity, and it might also generate the right conditions for the creation of new markets, as suggested by Porter and van der Linde (1995), with equally positive effects on productivity.

\subsection{Mediated effects and endogeneity concerns}

The literature on the PH emphasises the role of induced innovation as a means to (more than) offset environmental compliance costs. However, with few exceptions - such as Hamamoto (2006), Yang et al. (2012) and Lanoie et al. (2011) -, empirical analyses remain limited in scope. This is because either they focus only on the direct effect on patents (e.g. Johnstone et al. (2012), path (1) in Figure 1) or they investigate the overall effect of environmental regulatory stringency on indicators of economic performance, such as profits or productivity, with no explicit analysis of the mediating effect of innovation.

Our approach aims at filling this gap by decomposing the overall effect of our measures of environmental regulatory stringency on productivity into a direct effect and an indirect one, the latter being transmitted (mediated) by innovation. To do that we follow Lanoie et al. (2011) in taking into consideration the fact that regulation affects both innovation and productivity thus requiring to instrument innovation in the productivity equation.

To eliminate the bias arising from the endogeneity of patents in the productivity equation, we instrument patents with two different instruments: log of the average number of patents in the same sector but in other countries in the same year and $\log$ of the average number of patents in the same country but in other sectors in the same year. The idea is that the patenting performance of a country-sector is positively correlated with the two instruments: the propensity to patenting of a country as a whole (e.g. due to the availability of skilled labour force or public support to research that may influence all sectors) and its changes over time; and the features of a sector in terms of patenting intensity that is common across EU countries and its changes over time, which reflect general aggregate technological trends that are sector-specific. The above instruments should affect our dependent variable only through their effect on the endogenous variable. This is likely to be the case as only actual patenting is expected to lead to

\footnotetext{
${ }^{8}$ In particular, we tested for cross sectional independence and found that the null hypothesis of absence of cross-sectional dependence cannot be accepted. We also checked for autocorrelation and heteroskedasticity finding that, respectively, the null hypothesis of no serial correlation and null hypothesis of homoskedasticity are not accepted.

${ }^{9}$ This approach is particularly useful as it allows to do robust inference remaining in the framework of a straightforward fixed effect model.
} 
greater productivity while the patenting outcome of other countries or other sectors has an effect which is reasonably stronger on patenting (through knowledge spillovers) than on measured productivity (because imitation should be minimised by intellectual property rights embodied in patents).

Following Lanoie et al. (2011), the identification of the effect of environmental regulation that is mediated by innovation (here patents) is done by combining the estimated effects of our measures of regulatory stringency on innovation and the effect of innovation, properly instrumented, on productivity.

According to our assumptions about the lag structure, innovation at $t$ is influenced by regulation at $t-1$ and productivity at $t$ is influenced by innovation and regulation at $t-1$. This means that, in the end, productivity at $t$ is assumed to be directly influenced by regulation at $t-1$ and indirectly influenced by regulation at $t$ - 2 through innovation.

This approach allows us to investigate also path (2) and path (3) of Figure 1, thus providing a comprehensive picture of the full chain of links between environmental regulatory stringency and productivity.

\section{Data}

Our analysis is based on a longitudinal dataset covering 13 manufacturing sectors ${ }^{10}$ in eight European countries $^{11}$ over the 2001-2007 period. The panel includes 708 observations for a total of 103 sectorcountry pairs ${ }^{12}$. The following subsections briefly describe the data used as dependent and independent variables, a complete description of which is reported in Table 1.

[Table 1 about here]

\subsection{Dependent variables}

We use two sets of dependent variables to describe the performance of European manufacturing sectors. Innovative output is measured by means of EPO (European Patent Office) patent applications sorted by priority year and assigned to each manufacturing sector according to two alternative IPC-NACE concordance tables: the one developed by Lybbert and Zolas (2014) and the one developed by Schmoch et al. (2003). While the former tends to assign patents based on their 'sector of use' (Evenson et al., 1991), the latter follows a method of assignment which is more closely based on the 'industry of manufacture' approach. We are aware that the use of patent data can be affected by some drawbacks, among which the fact that they are biased towards product innovations and that not all inventions are patentable and patented. Nevertheless, patent data have been regarded as one of the best measures of technological innovation also because they are easily comparable across countries (Griliches, 1990).

As a further innovation variable, our analysis also considers environmental patents rather than total patents. As done in Brunnermeier and Cohen (2003), we try to determine whether environmental regulation may have a more specific impact on innovations that are directly related to environmental fields. Nevertheless, we argue that when a firm decides to comply with more stringent environmental regulations, it will be encouraged to change the quality of its products or the overall production process. Therefore, if the definition of environmental patent is particularly narrow in scope, these effects will be mainly captured by a general measure of innovation such as total patents or total R\&D expenditure. Environmental patents are here identified by means of their IPC and CPC (Cooperative Patent Classification) class and then assigned to sectors using the IPC-NACE concordance tables elaborated by Lybbert and Zolas (2014) and Schmoch et al. (2003). Environmentally relevant IPC/CPC classes are the ones selected by the OECD in the OECD-ENVTECH indicator ${ }^{13}$. These technologies include: General Environmental Management, Energy Generation from Renewable and Non-Fossil Sources, Combustion Technologies with Mitigation Potential, Technologies Specific to Climate Change Mitigation, Technologies

\footnotetext{
${ }^{10} \mathrm{NACE}$ rev. 1.1. DA: food products, beverages and tobacco. DB: textiles and textile products. DC: leather and leather products. DD: wood and wood products. DE: pulp, paper and paper products, publishing and printing. DF: coke, refined petroleum products and nuclear fuel. DG: chemicals, chemical products and man-made fibers. DH: rubber and plastic products. DI: other non-metallic mineral products. DJ: basic metals and fabricated metal products. DK: machinery and equipment n.e.c.. DL: electrical and optical equipment. DM: transport equipment. DN: manufacturing n.e.c..

${ }^{11}$ Austria (AT), Belgium (BE), the Czech Republic (CZ), Germany (DE), Italy (IT), the Netherlands (NL), Sweden (SE) and the United Kingdom (UK). In the 2001-2007 period, these eight countries accounted for about 77 percent of total EPO patent applications by EU applicants and for about 54 percent of total EU employment in manufacturing sectors.

${ }^{12}$ The potential size of the panel was 728 observations. However, some observations are missing for the Czech Republic: sector DF is missing for the entire period, while sector DA is missing for the years 2001, 2002, 2004 and 2006; sector DB_DC is missing for the year 2004, sector DD for the years 2001, 2002 and 2005, sector DE for the years 2001 and 2002, and sector DN for the year 2002 .

${ }^{13} \mathrm{http}$ ///www.oecd.org/env/consumption-innovation/indicator.htm
} 
with Potential or Indirect Contribution to Emission Mitigation, Emissions Abatement and Fuel Efficiency in Transportation, Energy Efficiency in Building and Lighting.

To check whether the strong $\mathrm{PH}$ is verified, we first use as our dependent variable a measure of productivity calculated as a TFP index. This variable, which is set to 100 in 1995 (base year), is part of a set of data built by EU-KLEMS ${ }^{14}$. TFP can be considered one of the most comprehensive synthetic measures of business performance since it describes how effectively inputs are transformed into economically valuable outputs. Nevertheless, we are aware of some limitations that may affect the measure of TFP. As discussed in O'Mahony and Timmer (2009), total factor productivity computed with growth accounting techniques as in EU-KLEMS provides a measure of disembodied technical change. However, it also captures any deviation from the neoclassical assumptions such as equalization of marginal costs with marginal revenues and perfect competition. To check the robustness of our results we use as an alternative measure real value added that is retrieved from the World Input Output Database (WIOD).

\subsection{Independent variables}

\subsubsection{Environmental regulation: within-sector, upstream and downstream regulation}

In the empirical literature environmental regulations are usually proxied by pollution abatement costs (Shadbegian and Gray, 2005; Brunnermeier and Cohen, 2003; Jaffe and Palmer, 1997). These studies are based on two key assumptions, i.e. that the above variables represent the main components of the costs borne by firms to comply with environmental regulations and that higher compliance costs reflect more stringent environmental regulations. However, this view has been criticised on the grounds that the interviewed firms find it increasingly difficult to quantify the portion of their expenditure and investments devoted to reducing environmental pressures and complying with regulations, also due to the increasingly popular use of integrated technologies rather than end-of-pipe solutions to environmental problems (Brunel and Levinson, 2013).

Conversely, in this paper the main variables of interest (i.e. our measures of environmental regulatory stringency) are proxied by environmental taxes (as a share of value added). Our idea is simple: the higher the amount of taxes, the tighter the regulations.

Data on environmental taxes are characterised by some key features which make them suitable for our purposes. Firstly, data on revenue from environmental taxes are available with sectoral breakdown for all economic branches as opposed to environmental protection expenditure, which is generally unavailable or aggregated for non-manufacturing sectors. This extremely detailed availability across all sectors makes it possible to build reliable indicators of upstream and downstream stringency. Secondly, differently from alternative discrete measures related to the introduction of specific environmental regulations, data on environmental taxes represent a continuous and time-varying measures of environmental regulatory stringency. Thirdly, as it is evident in Figure 2, the composition of environmental taxes is dominated by energy taxes in most countries, with the exception of Belgium in which energy taxes account for less than 50 percent of total environmental taxes in the period 2000-2002. Although one advantage of using such type of environmental regulations is that the intended outcome of energy taxes is to make fossil fuels directly or indirectly more expensive, sometimes the motivation behind the introduction of energy taxes is often not related to environmental issues.

\section{[Figure 2 about here]}

The use of environmental taxes also brings about some limitations. Despite their relevance and pervasiveness, they represent just one among many regulatory instruments for environmental purposes ${ }^{15}$. Secondly, energy taxes are sometimes introduced as a relatively efficient source of tax revenue (due to the inelastic nature of energy demand) or they may act as strategic fiscal tools to improve energy security (relevant for countries with limited natural and mineral resources) or to translate part of the fiscal burden on foreign producers of energy or suppliers of resources. Thirdly, in times of volatile energy prices, changes in energy taxes, that account for a big proportion of overall environmental taxes, represent in principle a relatively small fraction of the changes in total gross energy prices.

We use three different variables as measures of environmental regulatory stringency: within-sector intensity ${ }^{16}$ of environmental taxes, upstream average intensity, and downstream average intensity. Statistics

\footnotetext{
${ }^{14}$ The EU-KLEMS database contains, besides measures of productivity, other measures related to capital formation and employment. It was built thanks to a research project funded by the European Commission (FP6) and its aim was to produce comparable productivity estimates across countries and sectors. More information can be found at http://www.euklems.net.

${ }^{15} \mathrm{By}$ controlling for unobserved and time-invariant country-sector characteristic we also control for the average orientation of countries towards the use of environmental taxes as environmental policy tools as opposed to other possible tools.

${ }^{16}$ Intensity is defined as total sectoral revenues from environmental taxes (Eurostat) per unit of value added (WIOD).
} 
about revenues from environmental taxes with a sectoral breakdown are provided by Eurostat and can be found in the database 'Environmental taxes by economic activity'17. Regulation 691/2011 of the European Parliament and of the Council requires Member States to submit to Eurostat information on their revenue from environmentally related taxes by economic activities.

Upstream and downstream environmental tax intensities are computed by weighting the intensity of environmental taxes (per unit of value added) of all other production sectors of the economy, including other industrial sectors, agriculture and all service sectors. Weights are built by using the annual inputoutput tables from WIOD, which have the advantage of being available for each of the years considered. Being $\mathbf{Z}$ the square input-output matrix of domestic intermediate inputs, $\mathbf{x}$ the column vector of gross domestic output and $\mathbf{i}$ the summation column vector, the weighting matrix for upstream sectors is given by $\mathbf{Z}<\mathbf{Z}^{\prime} \mathbf{i}>^{-\mathbf{1}}$ while the weighting matrix for downstream sectors is given by $\mathbf{Z}<\mathbf{x}>^{-\mathbf{1}}{ }^{18}$ The aspects missing from this weighting approach are the regulations 'embodied' in imported intermediate inputs and the regulations 'embodied' in the portion of exports related to the intermediate inputs of partner countries. While estimates of inter-sectoral cross-country flows of intermediate inputs are reported in WIOD, no comprehensive information is currently available on environmental taxes for many trading partners, especially with a sectoral breakdown.

Upstream environmental tax intensity measures how much, on average (weighted by the importance of each supplying sector), suppliers spent on environmental taxes as a share of their value added. Similarly, downstream environmental taxes measure the average share of value added was spent in environmental taxes by downstream sectors.

\subsubsection{Controls}

We use specific controls for each category of dependent variables. For what concerns the knowledge production function, our choice of variables includes a number of factors which are among the most important determinants of product and process innovations. We adopt total employment (in terms of headcount, from WIOD) as a variable referring to the size of the sector. We expect that the larger is the sector, the higher the probability that firms in the sector will have enough resources to meet the costs inherent to start an innovation project and apply for patents. Knowledge stock is measured by means of the stock of EPO patents (with no distinction between environmental and non-environmental patents). The stock is built with the perpetual inventory method starting from 1977 (the year when the European Patent Office was established) and assuming a 15 percent depreciation rate. In this case, patents are assigned to the various sectors by using the IPC-NACE concordance table recently developed by Lybbert and Zolas (2014), which is particularly suitable as it tends to focus on the knowledge available to (and eventually used by) a sector ${ }^{19}$. As a measure of human capital we build an indicator of average wage (real gross compensation of employees - Eurostat - per employee - WIOD). This variable should account for the fact that better skills are more likely to bring about innovation outcomes and foster R\&D expenditure to a greater extent. As a measure of market structure, we use the share of large firms (more than 250 employees) by sector (OECD Structural Business Statistics). By adding this variable, we take into consideration that the concentration of the market can play an important role in the innovation process. However, as suggested in previous research, (Aghion et al., 2005), both extremely concentrated markets and extremely competitive markets can discourage and hinder innovation activities. Therefore we do not have any a priori expectations concerning the specific sign of this variable. Finally, we measure capital input in the extended production function by means of gross fixed capital formation in real terms, retrieved from WIOD.

\section{Results}

Table 2 reports the average values of some of our relevant variables by country and by sector while Table 3 shows some descriptive statistics for the variables used in the regression analysis. It can be seen that, in terms of innovation output (number of patents per 1,000 employees), the Netherlands stands out, followed by countries like Sweden and Germany. The same ranking can be observed also when

\footnotetext{
${ }^{17}$ http://epp.eurostat.ec.europa.eu/portal/page/portal/product_details/dataset?p_pro duct_code=ENV_AC_TAXIND

${ }^{18}$ To avoid double counting and limiting issues of multicollinearity, we set to zero the weights in the diagonal (taxes related to transaction with firms in the same sector) of the weighting matrices.

${ }^{19}$ If, in order to build the patent stock, we assign patents to sectors on the basis of the concordance table developed by Schmoch et al. (2003), the results are very similar in magnitude and statistical significance to the ones presented in the following section. For the sake of brevity, these results are not reported here but are available on request.
} 
considering environmental patents. When dealing with sectors, the ranking changes depending on the concordance table used. If the concordance by Lybbert and Zolas (2014) is adopted, the best performing sectors in terms of patents are sector DB_DC (textile and leather products) and DL (electrical and optical equipment). Conversely, when using the concordance by Schmoch et al. (2003), the three sectors with the highest patent intensity are DF (coke and refined petroleum products), DG (chemical products and man-made fibers) and DL. As for environmental taxes, it emerges that Italy, together with the Czech Republic, is one of the countries with the highest amount of within-sector taxes, but taxation levels are considerable also in downstream and upstream sectors (for which, however, the UK ranks second). Within-sector taxes are particularly high in energy intensive sectors such as DF, DG and DI (other non-metallic mineral products), while the sectors with the highest downstream environmental tax intensity are DI and DD (wood products). Sectors DF and DI, characterised by the highest within-sector environmental tax intensity, are also the ones with the greatest upstream environmental tax intensity.

Finally, Figure 3 describes aggregate trends of the intensity (per value added) of environmental taxes by country, aggregated for all manufacturing sectors. While the intensity of environmental taxes on value added tends to increase in the Czech Republic, Germany, the Netherlands and Belgium, a decrease is observed for Italy and no specific pattern, at least for the manufacturing sector as a whole, is detectable in other countries.

[Table 2 about here]

[Table 3 about here]

[Figure 3 about here]

Before commenting on the results of our econometric exercise, it is important to discuss the extent to which our variables correlate with each other. The correlation matrix (Table 4) for our variables of interes $^{20}$ shows a rather high correlation value between upstream and downstream environmental tax intensity (about 0.9), across various measures of patents and between average wages and various measures of sector performance (TFP, value added and patent stock) while all other correlations are smaller than 0.5. The strong correlation between upstream and downstream environmental tax intensity is particularly relevant for our analysis. This is why the estimates in which the two measures appear together should be interpreted with particular care.

\section{[Table 4 about here]}

Table 5 shows the first step of our estimation strategy, which concerns the effects of environmental taxes on patents. Panel A reports estimates obtained by assigning patents to sectors according to the Lybbert and Zolas (2014) concordance table (labelled as LZ), while in panel B patents are matched using the Schmoch et al. (2003) concordance table (labelled as ES). In column 1 we estimate a benchmark model, which only includes the most common drivers of innovation output. The results obtained are in line with our expectations: knowledge stock and human capital (expressed here in terms of average wage), which are the traditional inputs of any knowledge production function, positively affect patent applications ${ }^{21}$. This accounts for the fact that the workers' skills are a crucial determinant of innovation activities. Labour input is also positive and significant for both dependent variables, indicating that a bigger sector fosters higher levels of innovation. Finally, patenting is positively influenced by changes in the presence of large firms within a sector, due to their greater propensity to patenting, but the effect is not statistically different from zero when we adopt the concordance table proposed by Schmoch et al. (2003).

\section{[Table 5 about here]}

From column 2 onwards we add our main variables of interest one by one ${ }^{22}$. We notice a strong, positive and significant effect of upstream and downstream stringency, confirming the induced innovation hypothesis. When considering within-sector environmental taxation we obtain very small coefficients,

\footnotetext{
${ }^{20}$ Correlation is computed based on the within transformation of the variables.

${ }^{21}$ Average wage for Schmoch et al. (2003) is not significant in the baseline regressions but turns out to be significant when adding our set of measures of regulatory stringency.

${ }^{22}$ Our variables of environmental regulatory stringency have been transformed into Z-scores: this means subtracting from the variable the sample average and dividing by the standard deviation, thus obtaining a variable with zero mean and standard deviation equal to one. Estimated coefficients should be interpreted as percentage change in the dependent variable due to an increase of one standard deviation in the measure of environmental regulatory stringency.
} 
which are not statistically different from zero, in line with the findings of Jaffe and Palmer (1997). The traditional channel referred to in the weak version of the $\mathrm{PH}$ does not seem to be active in our case.

For what concerns patents based on the concordance table by Lybbert and Zolas (2014), the effect of downstream inducement (column 4) is positive and greater in magnitude than the effect of upstream inducement (16.5 percent increase in patents for a one standard deviation increase in downstream environmental tax intensity). However, when the three measures are considered together, although the effect of downstream environmental taxes remains positive and significant, the effect of upstream taxes turns out to be negative and significant. While more stringent regulations in downstream sectors generate opportunities for innovation, we observe that higher upstream environmental tax intensity constitutes a constraint which hinders innovation activities and has a negative effect. A similar but much weaker result is found when analysing patents based on the concordance table by Schmoch et al. (2003). When introduced separately, both upstream and downstream environmental taxes have an inducement effect in terms of more patents but the coefficients in this case are much smaller than the results based on the concordance table by Lybbert and Zolas (2014) (5.6 per cent increase in patents for a one standard deviation increase in downstream environmental tax intensity). Yet, when considered together, only downstream environmental taxes appear to induce innovation, while the effect of upstream taxes is no longer significant.

On the whole, the 'downstream' channel seems to be the strongest of the three measures when considering the weak version of the PH. This is in line with most of the theoretical literature reviewed in section 2.1, which focuses on the role played by the demand for better technologies put forward by more heavily regulated downstream firms and sectors to their suppliers.

[Table 6 about here]

The results for our productivity equation are reported in Table $6 .{ }^{23}$ First, we observe that lagged patents have a positive influence on productivity, and this effect is significant in all specifications. The only exception is a coefficient close to 10 percent significance for the case of TFP and patents assigned according to the concordance table by Lybbert and Zolas (2014). Excluded instruments are jointly sufficiently strong ( $F$ test on excluded instruments is greater than the usual cut-off level of 10) in all specifications and based on the test on over-identifying restrictions (Hansen's J test), we cannot reject the null hypothesis of validity of the restrictions.

If we combine this positive effect of patents at $t-1$ on productivity at $t$ with the positive effect of downstream environmental tax intensity at $t-1$ on patents at $t$, we obtain an estimate of the effect of downstream environmental tax intensity at $t-2$ on productivity at $t$ which is equal to the product of the two estimated coefficients. If we combine the results found in column 5 of panel A of Table 5 with the ones reported in column 5 of panel B of Table 6, which is our upper bound, following Lanoie et al. (2011) we estimate that a one standard deviation increase in the intensity of downstream environmental taxes in t-2 has an indirect (i.e. mediated by patents) positive effect on productivity equal to about 4.6 percent $(0.183 \times 0.252)$ while the direct effect of a one standard deviation increase in downstream environmental taxes in the same specification increases productivity of about 15 percent.

It is interesting to note, however, that environmental taxes also have a strong direct (i.e. not mediated by patents) effect on productivity. We observe that the within-sector intensity of environmental taxes is positively and significantly related to productivity in all specifications, the effect ranging between 4.63 and 7.91 percent productivity increase for a one standard deviation increase in within-sector environmental tax intensity. This result highlights the fact that within-sector environmental taxes are not mediated by innovations which can be measured by patents but they influence productivity through other channels, such as process innovations (which cannot be properly measured by patents, especially when using concordance tables to assign patents to sectors) or organisational innovations. When looking at upstream and downstream environmental tax intensity, we observe that, differently from what we found for the knowledge production function, no significant effect emerges if these two measures are individually included in the productivity equations. On the other hand, the results for column 5 highlight a significant, positive and sizeable effect of downstream environmental tax intensity on productivity and significant and negative effect of upstream environmental tax intensity on productivity.

[Table 7 about here]

\footnotetext{
${ }^{23}$ While in Table 6 we account for the endogeneity of patents, Table 8 in the Appendix reports the same but without considering said endogeneity. The results are qualitatively very similar, the only difference being that when we do not account for endogeneity we generally observe a downward bias in the coefficients of the three measures of environmental regulation and in the coefficient of patents. On the other hand, standard errors in the IV approach tend to be much higher.
} 
As mentioned above, it might be useful to separate environmental patents from total patents. As done by Brunnermeier and Cohen (2003), we use a measure of environmental patents as dependent variable in the knowledge production function and as explanatory variable in the productivity equation. Results are reported in Table 7. In column 1 we report the results for the knowledge production function with environmental patents as dependent variable. Independently of the choice made in relation to the IPC-NACE concordance, we observe a strong positive effect of downstream environmental tax intensity on environmental patents but also negative and significant effects of within-sector and upstream environmental tax intensity. These negative effects of regulation within sector and in upstream sectors on environmental patents can be due to the fact that environmental patents only capture a specific portion of the set of technological innovations that a firm has to develop and adopt to comply with tighter environmental regulations. Nevertheless, when considering the process of innovation to comply with tighter environmental regulations, we suppose that a greater reorganization of production process can occur that encompasses a broader definition of innovation than the one we use for our measure of environmental patents.

When we look at the productivity equation, we observe that, with only one exception, the effect of environmental patents on productivity is not significant. ${ }^{24}$ Nevertheless, it should be noted that our instruments (which are now built using environmental patents in other sectors and countries rather than total patents) are too weak (the F test of excluded IVs is always below 10), thus limiting the reliability of these estimates. For this reason, we also report (likely endogenous) estimates in which we do not instrument environmental patents (columns 2 and 3). In brief, even though environmental patents are affected by regulation, they do not act as mediators in the relationship between regulation and productivity, differently from what happens in the case of total patents.

\section{Conclusions}

The costs to comply with environmental requirements used to be interpreted as a further private cost imposed on firms, which lead to lower competitiveness. This narrow view of environmental policy was later challenged, most notably in works by Porter (Porter, 1991; Porter and van der Linde, 1995), who put forward the hypothesis that properly designed, more stringent environmental regulations can improve firms' innovation and productivity thus reverberating positively on sectors and country competitiveness.

Although different versions of the $\mathrm{PH}$ have been investigated in various studies, we propose a theoretically similar but empirically different exercise. In this paper we take the analysis of the PH one step further, by looking at the extent to which its strong and weak versions can be considered valid when applied to the manufacturing sectors of 8 European countries over the 2001-2007 period. The innovative aspect introduced is that we account for the inducement which each sector may receive from regulations not only in the same sector but also in related upstream and downstream sectors. This has been made possible by using country- and year-specific input-output data from the WIOD. In particular, we focus on the role played by environmental taxes, a measure which has hardly ever been used to test the PH. The reason why we use this type of regulation is that it is particularly suitable to test the PH. Firstly, it represents a market-based measure rather than a command-and-control measure. Secondly, data on environmental taxes are available for a rather long time span and at the country-industry level. Another innovative aspect of our work is that we measure not only the 'direct' effect of environmental taxes on patents and productivity respectively, but also their 'indirect' effect on productivity mediated by induced innovation. We do this, empirically, by using an IV approach in which we account for the endogeneity of patents in the productivity equation, therefore also accounting for a sort of 'indirect' effect that patents may have on productivity. In this way we are able to provide a more complete empirical test of the $\mathrm{PH}$.

First of all, our results find support both for the weak and the strong version of the PH. This is a valuable result which stress the idea that environmental regulation, contrary to the conventional wisdom, can be the source of greater competitiveness. This result obtained for European countries is partly in line with Rubashkina et al. (2015) who find only support for the weak version. Our results reveal that the strongest effects on both patents and productivity can be ascribed to downstream taxes. This is one of the main contributions of our work as all the other studies only focus on within-sector type of regulation and do not address inter sectoral linkages. Among the explanation we can give is that higher taxes imposed on downstream sectors induce their corresponding upstream sectors to innovate, in order to generate new intermediate goods which can improve the energy efficiency and environmental performance of the downstream sectors. Thus, upstream sectors act as specialised suppliers of technology, as described in the

\footnotetext{
${ }^{24}$ Worter et al. (2013) analyse a panel of manufacturing industries in 12 OECD countries and estimate that there exists an U-shape relationship at the sectoral level between green innovation and productivity. Moreover, they underline that the turning point occurs at a very high level of green patenting which is relevant for just few sectors in their sample.
} 
theoretical model by Heyes and Kapur (2011) and, more generally, in the literature reviewed in section 2.1. These types of taxes also have an extremely strong effect on productivity. For this measure, we find confirmation of both the weak and strong version of the PH. Once controlling for downstream regulation, we also observe a generally negative effect of upstream regulation both on productivity and on patents. While downstream regulation generates opportunities for innovation and may create markets for new and improved intermediate goods, upstream regulation acts as a constraint which negatively affects innovation and, even more strongly, productivity. Finally, the traditional within-sector measure of regulation has no effect on patents but a positive and significant effect on productivity. The various sectors tend to react to direct environmental regulations by means of innovations which cannot be effectively measured by patents, such as process innovations (e.g. energy efficient machinery) or organizational innovations.

Our results may suggest some interesting implications for policy as well as for firm strategies. In the first place, policy makers should consider with care how environmental regulations affect both those sectors that are directly hit by the regulation and those sectors that are linked to the former by means of upstream and downstream linkages. According to our finding, we observe that downstream sectors are the main 'winners' in terms of productivity improvement while the productivity of upstream sectors is negatively affected by environmental taxes. These indirect effects should be carefully considered both in ex ante and ex post policy evaluation. In the second place, our results underlines the importance of downstream sectors (e.g. specialized suppliers of equipment) as a source of knowledge to cope with more stringent environmental regulations. Knowledge generated as a consequence of more stringent environmental regulation benefits both those firms and sectors that exploit this newly generated knowledge as well as those firms and sectors that can use it to reduce their compliance costs. 


\section{References}

Aghion, P., N. Bloom, R. Blundell, R. Griffith, and P. Howitt (2005). Competition and Innovation: An Inverted-U Relationship. The Quarterly Journal of Economics 120(2), 701-728.

Ambec, S., M. Coheny, S. Elgiez, and P. Lanoie (2013). The Porter Hypothesis at 20: Can environmental regulation enhance innovation and competitiveness? Review of Environmental Economics and Policy 7(1), 2-22.

Broberg, T., P.-O. Marklund, E. Samakovlis, and H. Hammar (2013). Testing the Porter hypothesis: the effects of environmental investments on efficiency in Swedish industry. Journal of Productivity Analysis 40(1), 43-56.

Brunel, C. and A. Levinson (2013). Measuring environmental regulatory stringency. OECD Trade and Environment Working Papers, OECD.

Brunnermeier, S. B. and M. A. Cohen (2003). Determinants of environmental innovation in US manufacturing industries. Journal of Environmental Economics and Management 45, 278-293.

Carrion-Flores, C. E. and R. Innes (2010). Environmental innovation and environmental performance. Journal of Environmental Economics and Management 59(1), 27-42.

Costantini, V. and M. Mazzanti (2012). On the green and innovative side of trade competitiveness? The impact of environmental policies and innovation on EU exports. Research Policy 41, 132-153.

Crepon, B., E. Duguet, and J. Mairesse (1998). Research, Innovation And Productivity: An Econometric Analysis At The Firm Level. Economics of Innovation and New Technology 7(2), 115-158.

Driscoll, J. C. and A. C. Kraay (1998). Consistent covariance matrix estimation with spatially dependent panel data. Review of Economics and Statistics 80, 549-560.

Evenson, R. E., J. Putnam, and S. Kortum (1991). Estimating patent counts by industry using the Yale-Canada concordance. Final report, National Science Foundation.

Ford, J. A., J. Steen, and M.-L. Verreynne (2014). How environmental regulations affect innovation in the Australian oil and gas industry: going beyond the Porter Hypothesis. Journal of Cleaner Production 84, 204-213.

Ghisetti, C. and F. Quatraro (2013). Beyond inducement in climate change: Does environmental performance spur environmental technologies? A regional analysis of cross-sectoral differences. Ecological Economics 96, 99-113.

Gollop, F. M. and M. J. Roberts (1983). Environmental regulations and productivity growth: The case of fossil-fueled electric power generation. Journal of Political Economy 91(4), 654-74.

Gray, W. B. and R. J. Shadbegian (1998). Environmental regulation, investment timing, and technology choice. Journal of Industrial Economics 46(2), 235-56.

Gray, W. B. and R. J. Shadbegian (2003). Plant vintage, technology, and environmental regulation. Journal of Environmental Economics and Management 46(3), 384-402.

Greaker, M. (2006). Spillovers in the development of new pollution abatement technology: A new look at the Porter-hypothesis. Journal of Environmental Economics and Management 52(1), 411-420.

Griliches, Z. (1979). Issues in assessing the contribution of research and development to productivity growth. Bell Journal of Economics 10(1), 92-116.

Griliches, Z. (1990). Patent statistics as economic indicators: A survey. Journal of Economic Literature 28(4), 1661-1707.

Hamamoto, M. (2006). Environmental regulation and the productivity of Japanese manufacturing industries. Resource and Energy Economics 28, 299-312.

Heyes, A. and S. Kapur (2011). Regulatory attitudes and environmental innovation in a model combining internal and external R\&D. Journal of Environmental Economics and Management 61(3), 327-340. 
Hoechle, D. (2007). Robust standard errors for panel regressions with cross-sectional dependence. The Stata Journal 7, 281-312.

Hoel, M. (1994). Environmental policy as a game between governments when plant locations are endogenous. University of Oslo, Department of Economics.

Iraldo, F., F. Testa, M. Melis, and M. Frey (2011). A literature review on the links between environmental regulation and competitiveness. Environmental Policy and Governance 21(3), 210-222.

Jaffe, A. and K. Palmer (1997). Environmental regulation and innovation: a panel data study. Review of Economics and Statistics 79 (4), 610-619.

Johnstone, N., I. Haščič, J. Poirier, M. Hemar, and C. Michel (2012). Environmental policy stringency and technological innovation: evidence from survey data and patent counts. Applied Economics 44(17), $2157-2170$.

Johnstone, N., I. Hascic, and D. Popp (2010). Renewable energy policies and technological innovation: evidence based on patent counts. Environmental and Resource Economics 45, 133-155.

Kneller, R. and E. Manderson (2012). Environmental regulations and innovation activity in UK manufacturing industries. Resource and Energy Economics 34(2), 211-235.

Lanoie, P., J. Laurent-Lucchetti, N. Johnstone, and S. Ambec (2011). Environmental policy, innovation and performance: New insights on the Porter Hypothesis. Journal of Economics \& Management Strategy 20(3), 803-842.

Lanoie, P., M. Patry, and r. Lajeunesse (2008). Environmental regulation and productivity: New findings on the Porter Hypothesis. Journal of Productivity Analysis 30, 121--128.

Leiter, A. M., A. Parolini, and H. Winner (2011). Environmental regulation and investment: Evidence from European industry data. Ecological Economics 70(4), 759-770.

Lybbert, T. J. and N. J. Zolas (2014). Getting patents and economic data to speak to each other: An 'algorithmic links with probabilities' approach for joint analyses of patenting and economic activity. Research Policy 43(3), 530-542.

Managi, S., J. J. Opaluch, D. Jin, and T. A. Grigalunas (2005). Environmental regulations and technological change in the offshore oil and gas industry. Land Economics 81(2), 303-319.

Mohnen, P. and G. Van Leeuwen (2015). Revisiting the Porter Hypothesis: an empirical analysis of green innovation for the Netherlands. UNU-MERIT Working Paper Series 2, UNU-MERIT.

Mohr, R. D. (2002). Technical change, external economies, and the Porter Hypothesis. Journal of Environmental Economics and Management 43(1), 158-168.

O'Mahony, M. and M. P. Timmer (2009). Output, input and productivity measures at the industry level: the EU KLEMS database. The Economic Journal 119, F374-F403.

Perino, G. (2010). Technology diffusion with market power in the upstream industry. Environmental and Resource Economics 46(4), 403-428.

Popp, D. (2006). International innovation and diffusion of air pollution control technologies: the effects of NOX and SO2 regulation in the US, Japan, and Germany. Journal of Environmental Economics and Management 51(1), 46-71.

Porter, M. (1991). America's green strategy. Scientific American 264(4), 168.

Porter, M. and C. van der Linde (1995). Toward a new conception of the environment-competitiveness relationship. Journal of Economic Perspectives 9 (4), 97--118.

Rexhäuser, S. and C. Rammer (2014). Environmental innovations and firm profitability: Unmasking the Porter hypothesis. Environmental and Resource Economics 57(1), 145-167.

Rubashkina, Y., M. Galeotti, and E. Verdolini (2015). Environmental regulation and competitiveness: Empirical evidence on the Porter Hypothesis from European manufacturing sectors. Energy Policy 83, 288-300. 
Schmoch, U., F. Laville, P. Patel, and R. Frietsch (2003). Linking technology areas to industrial sectors. Final Report to the European Commission, DG Reasearch European Commission.

Shadbegian, R. J. and W. B. Gray (2005). Pollution abatement expenditures and plant-level productivity: A production function approach. Ecological Economics 54(2-3), 196-208.

Sugeta, H. and S. Matsumoto (2007). Upstream and downstream pollution taxations in vertically related markets with imperfect competition. Environmental and Resource Economics 38(3), 407-432.

Ulph, A. and L. Valentini (1997). Plant location and strategic environmental policy with inter-sectoral linkages. Resource and Energy Economics 19(4), 363-383.

Worter, M., T. Stucki, and C. Soltmann (2013). The Performance Effect of Environmental Innovations. KOF Working papers 13-330, KOF Swiss Economic Institute, ETH Zurich.

Xepapadeas, A. and A. de Zeeuw (1999). Environmental Policy and Competitiveness: The Porter Hypothesis and the Composition of Capital. Journal of Environmental Economics and Management 37(2), $165-182$.

Yang, C.-H., Y.-H. Tseng, and C.-P. Chen (2012). Environmental regulations, induced R\&D, and productivity: Evidence from Taiwan's manufacturing industries. Resource and Energy Economics 34(4), $514-532$. 


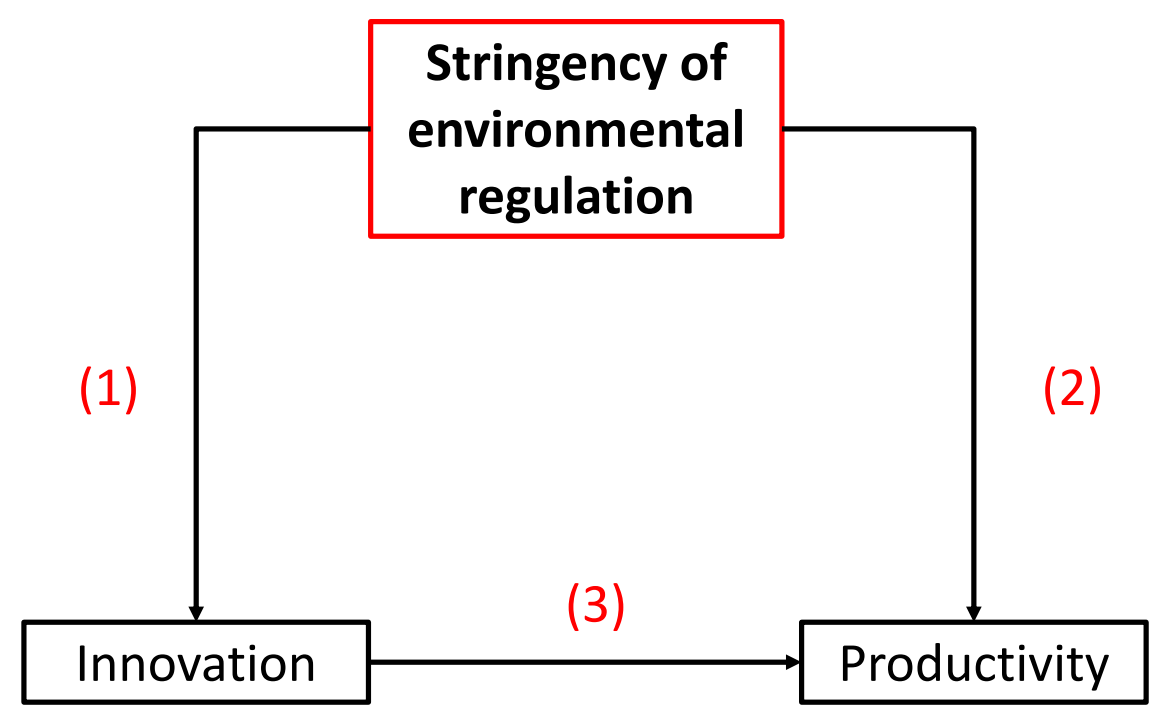

Table 1: Definition and sources of variables

\begin{tabular}{|c|c|}
\hline Var. name & Definition \\
\hline $\mathrm{L}$ & Total employment (headcounts; WIOD database) \\
\hline Patent_LZ & $\begin{array}{l}\text { Total EPO patent count (REG-PAT, attributed to sectors by using the concordance proposed } \\
\text { by Lybbert and Zolas }(2014) \text { ) }\end{array}$ \\
\hline Patent_ES & Total EPO patent count (Eurostat) \\
\hline EnvPat_LZ & $\begin{array}{l}\text { Count of environmental EPO patents (OECD definition based on IPC classes; REG-PAT } \\
\text { database, with patents attributed to sectors by using the Lybbert and Zolas (2014) IPC-NACE } \\
\text { concordance) }\end{array}$ \\
\hline EnvPat_ES & $\begin{array}{l}\text { Count of environmental EPO patents (OECD definition based on IPC classes; REG-PAT } \\
\text { database, with patents attributed to sectors by using the Schmoch et al. (2003) IPC-NACE } \\
\text { concordance) }\end{array}$ \\
\hline VA & Value added (WIOD database) \\
\hline Inv & Gross fixed capital formation (WIOD database) \\
\hline Average wage & $\begin{array}{l}\text { Ratio between total real wages paid to employees (Eurostat) and total number of employees } \\
\text { (WIOD) }\end{array}$ \\
\hline Share big firms & Number of firms with more than 250 employees by sector (OECD Structural Business Statistics) \\
\hline TFP & Index of TFP growth (=100 in 1995, EUKLEMS) \\
\hline Patent stock & $\begin{array}{l}\text { Stock of EPO patents (perpetual inventory method, first year 1977, depreciation } 15 \text { percent) } \\
\text { assigned to sectors using the concordance proposed by Lybbert and Zolas (2014) (REG-PAT } \\
\text { database) }\end{array}$ \\
\hline
\end{tabular}


Figure 2: Composition of environmental taxes by category

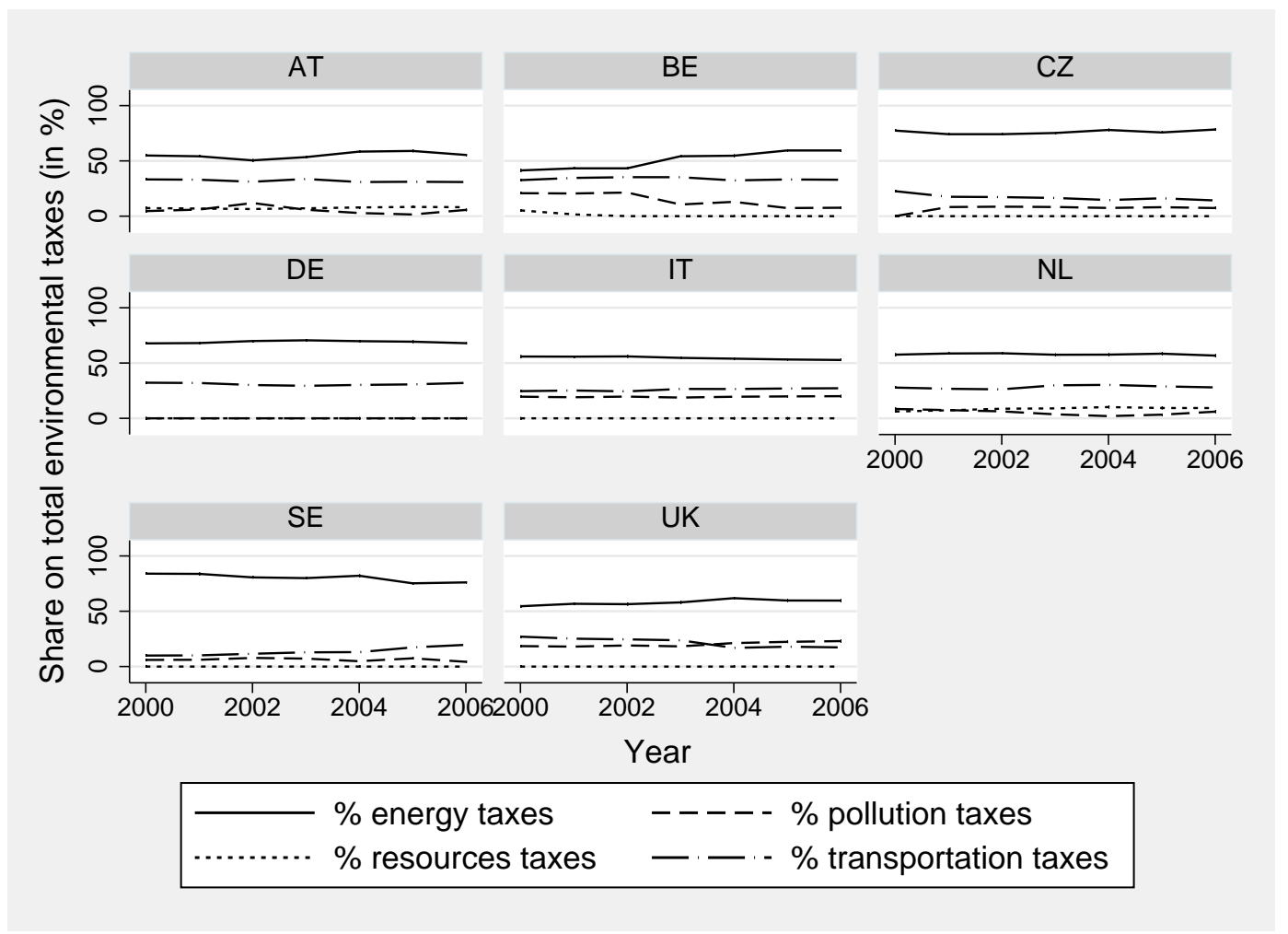

Table 2: Averages by country and sector

\begin{tabular}{|c|c|c|c|c|c|c|c|c|c|c|}
\hline Country & Patent_LZ/L & Patent_ES/L & PatEnv_LZ/L & PatEnv_ES/L & $\mathrm{R} \& \mathrm{D} / \mathrm{VA}$ & $\begin{array}{l}\text { Average } \\
\text { wage }\end{array}$ & $\begin{array}{c}\text { Share big } \\
\text { firms }\end{array}$ & $\begin{array}{l}\text { Within } \\
\text { tax/VA }\end{array}$ & $\begin{array}{c}\text { Downstr } \\
\text { tax/VA }\end{array}$ & $\begin{array}{c}\text { Upstr } \\
\operatorname{tax} / V A\end{array}$ \\
\hline AT & 2.0080 & 3.0359 & 0.0848 & 0.1538 & 88.5369 & 45.0638 & 0.0380 & 0.0198 & 2.5688 & 4.3173 \\
\hline $\mathrm{BE}$ & 1.7855 & 2.3601 & 0.0701 & 0.0905 & 72.1268 & 47.5969 & 0.0289 & 0.0054 & 1.9476 & 3.2359 \\
\hline $\mathrm{CZ}$ & 0.0681 & 0.1190 & 0.0037 & 0.0082 & 11.5854 & 6.6417 & 0.0202 & 0.0416 & 5.9205 & 8.2820 \\
\hline DE & 3.1383 & 3.5613 & 0.1670 & 0.1759 & 57.7770 & 40.4018 & 0.0485 & 0.0150 & 3.3073 & 5.8981 \\
\hline IT & 0.7809 & 1.2852 & 0.0308 & 0.0536 & 46.2670 & 29.7399 & 0.0079 & 0.0382 & 7.0267 & 12.3241 \\
\hline $\mathrm{NL}$ & 5.3696 & 4.0788 & 0.2131 & 0.2432 & 67.2779 & 39.8275 & 0.0284 & 0.0155 & 2.0401 & 3.7450 \\
\hline $\mathrm{SE}$ & 3.5206 & 3.1091 & 0.1192 & 0.1141 & 91.0719 & 54.5606 & 0.0157 & 0.0094 & 3.7634 & 6.5300 \\
\hline UK & 1.1390 & 1.3764 & 0.0435 & 0.0595 & 48.2854 & 37.6536 & 0.0240 & 0.0217 & 6.7057 & 10.6768 \\
\hline DA & 0.9456 & 0.4949 & 0.0257 & 0.0036 & 49.8060 & 31.2525 & 0.0170 & 0.0159 & 1.8746 & 5.0545 \\
\hline DB_DC & 6.3218 & 0.4308 & 0.2402 & 0.0037 & 39.4970 & 30.1591 & 0.0070 & 0.0149 & 2.0535 & 4.9026 \\
\hline DD & 0.8489 & 0.1108 & 0.0222 & 0.0031 & 46.2216 & 33.0427 & 0.0029 & 0.0200 & 7.0625 & 8.9343 \\
\hline $\mathrm{DE}$ & 1.1870 & 0.3292 & 0.0106 & 0.0025 & 58.1084 & 37.6561 & 0.0090 & 0.0133 & 5.3574 & 7.7892 \\
\hline DF & 3.8416 & 7.3854 & 0.2742 & 0.2570 & 137.6510 & 45.8058 & 0.1321 & 0.0649 & 6.4876 & 12.4725 \\
\hline DG & 4.5205 & 7.2749 & 0.1113 & 0.3226 & 102.9088 & 50.6358 & 0.0547 & 0.0436 & 2.3387 & 3.4065 \\
\hline $\mathrm{DH}$ & 0.4867 & 1.0454 & 0.0214 & 0.0511 & 48.2400 & 33.2806 & 0.0224 & 0.0107 & 6.0911 & 7.6859 \\
\hline DI & 1.2902 & 1.0421 & 0.1151 & 0.0752 & 51.8925 & 34.9153 & 0.0130 & 0.0291 & 9.2135 & 11.9956 \\
\hline DJ & 1.0175 & 0.7209 & 0.0768 & 0.0591 & 48.3148 & 35.0588 & 0.0076 & 0.0154 & 4.5978 & 5.6380 \\
\hline DK & 2.4062 & 2.3640 & 0.1327 & 0.2561 & 47.9172 & 34.7617 & 0.0184 & 0.0098 & 2.1396 & 5.8104 \\
\hline $\mathrm{DL}$ & 4.9511 & 7.1391 & 0.1342 & 0.2503 & 88.7824 & 67.6631 & 0.0138 & 0.0065 & 2.4261 & 4.1926 \\
\hline DM & 1.1481 & 2.7064 & 0.0516 & 0.2045 & 56.1737 & 40.1448 & 0.0522 & 0.0074 & 1.5026 & 3.5697 \\
\hline DN & 0.7437 & 0.6680 & 0.0155 & 0.0018 & 33.3751 & 26.4300 & 0.0050 & 0.0166 & 2.6720 & 8.2100 \\
\hline Total & 2.2872 & 2.4292 & 0.0940 & 0.1153 & 61.7440 & 38.5627 & 0.0266 & 0.0202 & 4.1103 & 6.8364 \\
\hline
\end{tabular}

Table 3: Descriptive statistics

\begin{tabular}{rccccc}
\hline Variable & Mean & Median & SD & Min & Max \\
\hline $\log ($ patent_LZ, t) & 4.584 & 4.729 & 1.755 & -2.447 & 8.325 \\
$\log ($ patent_ES, t) & 4.397 & 4.374 & 1.928 & -1.528 & 8.901 \\
$\log ($ env_pat_LZ, t) & 1.758 & 1.624 & 1.288 & 0.000 & 5.686 \\
$\log ($ env_pat_ES, t) & 1.640 & 1.188 & 1.630 & 0.000 & 6.543 \\
TFP, t & 1.236 & 1.121 & 0.669 & 0.222 & 9.495 \\
$\log (\mathrm{VA}, \mathrm{t})$ & 8.453 & 8.469 & 1.253 & 5.607 & 11.569 \\
$\log ($ patent stock, t-1) & 5.986 & 6.149 & 1.909 & 0.066 & 9.830 \\
$\log ($ average wage, t-1) & 3.480 & 3.588 & 0.642 & 1.191 & 5.765 \\
$\log (\mathrm{L}, \mathrm{t}-1)$ & 4.530 & 4.502 & 1.264 & 0.488 & 7.026 \\
Share big firms, t-1 & 0.027 & 0.014 & 0.041 & 0.000 & 0.322 \\
$\log ($ inv, t-1) & 6.693 & 6.649 & 1.223 & 1.699 & 9.644 \\
Within env tax, t-1 & 0.020 & 0.012 & 0.039 & 0.000 & 0.465 \\
Upstream env tax, t-1 & 4.110 & 3.204 & 3.541 & 0.169 & 18.908 \\
Downstream env tax, t-1 & 6.836 & 5.781 & 4.940 & 0.460 & 34.376 \\
\hline & & & & & \\
\hline
\end{tabular}


Figure 3: Environmental tax intensity of value added by country

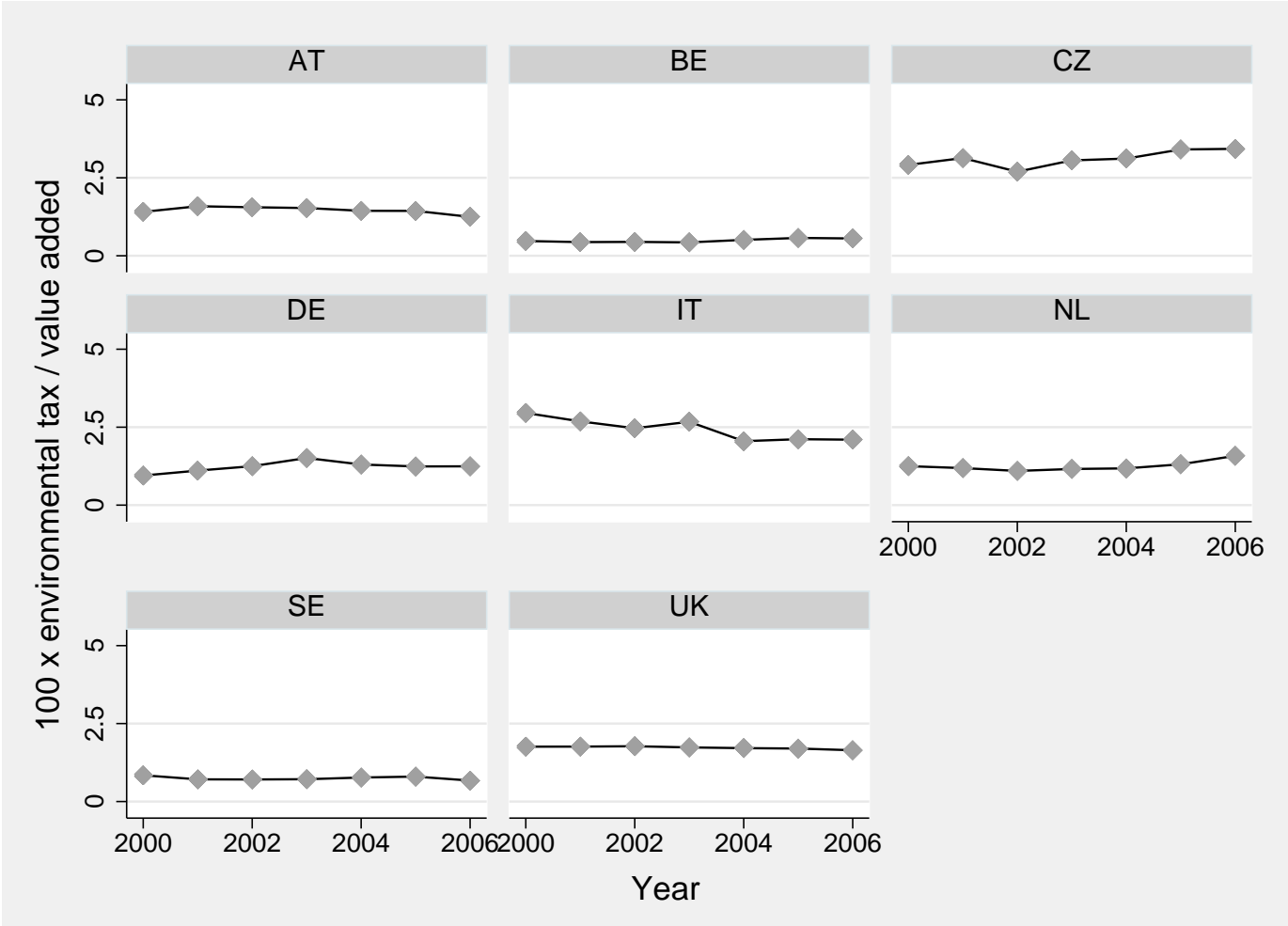

Table 4: Correlation matrix

\begin{tabular}{|c|c|c|c|c|c|c|c|c|}
\hline & & (1) & (2) & (3) & (4) & (5) & (6) & (7) \\
\hline (1) & $\log ($ patent_LZ, $t)$ & 1 & & & & & & \\
\hline (2) & $\log ($ patent_ES, $t)$ & 0.6642 & 1 & & & & & \\
\hline (3) & $\log ($ env_pat_LZ, $t)$ & 0.1923 & 0.1586 & 1 & & & & \\
\hline (4) & $\log ($ env_pat_ES, $\mathrm{t})$ & 0.0855 & 0.1562 & 0.5583 & 1 & & & \\
\hline (5) & TFP, $\mathrm{t}$ & 0.2559 & 0.3085 & 0.1249 & 0.0726 & 1 & & \\
\hline (6) & $\log (\mathrm{VA}, \mathrm{t})$ & 0.3307 & 0.3879 & 0.1382 & 0.0759 & 0.7376 & 1 & \\
\hline (7) & $\log ($ patent stock, $t-1)$ & 0.4212 & 0.7053 & 0.2260 & 0.1843 & 0.3902 & 0.4917 & 1 \\
\hline (8) & $\log ($ average wage, $t-1)$ & 0.3037 & 0.4164 & 0.1156 & 0.0529 & 0.6061 & 0.6722 & 0.5472 \\
\hline (9) & $\log (\mathrm{L}, \mathrm{t}-1)$ & -0.0810 & -0.2454 & -0.0628 & -0.0582 & -0.1948 & 0.1013 & -0.3833 \\
\hline (10) & Share big firms, t-1 & -0.0173 & $\begin{array}{l}-0.2404 \\
-0.0593\end{array}$ & 0.0333 & 0.0271 & -0.0366 & -0.0754 & -0.0975 \\
\hline (11) & $\log (\mathrm{inv}, \mathrm{t}-1)$ & 0.0051 & -0.0313 & -0.0115 & 0.0057 & -0.0266 & 0.1148 & -0.0705 \\
\hline (12) & Within env tax, t-1 & 0.0606 & 0.0359 & -0.0370 & -0.1107 & 0.0547 & 0.1924 & 0.0426 \\
\hline (13) & Upstream env tax, t-1 & 0.0643 & -0.0115 & 0.0215 & -0.0235 & -0.0449 & -0.0006 & -0.0885 \\
\hline \multirow[t]{2}{*}{ (14) } & Downstream env tax, $t-1$ & 0.0214 & -0.0342 & -0.0268 & -0.0885 & -0.0835 & -0.0443 & -0.1074 \\
\hline & & (8) & (9) & (10) & (11) & (12) & (13) & (14) \\
\hline (8) & $\log ($ average wage, $t-1)$ & 1 & & & & & & \\
\hline (9) & $\log (\mathrm{L}, \mathrm{t}-1)$ & -0.3702 & 1 & & & & & \\
\hline (10) & Share big firms, t-1 & $\begin{array}{l}-0.0102 \\
-0.1335\end{array}$ & 0.0458 & 1 & & & & \\
\hline (11) & $\log ($ inv,$t-1)$ & -0.0962 & 0.2763 & 0.0661 & 1 & & & \\
\hline (12) & Within env tax, t-1 & 0.3584 & -0.0657 & -0.0209 & -0.0669 & 1 & & \\
\hline (13) & Upstream env tax, t-1 & -0.1551 & 0.2541 & 0.1242 & 0.1468 & 0.1769 & 1 & \\
\hline (14) & Downstream env tax, $t-1$ & -0.1961 & 0.2625 & 0.1396 & 0.2136 & 0.2051 & 0.9050 & 1 \\
\hline
\end{tabular}


Table 5: Knowledge production function (total patents)

\begin{tabular}{|c|c|c|c|c|c|}
\hline Dep: $\log ($ patent_LZ, $t)$ & $\frac{\text { PANEL }}{(1)}$ & $\frac{-\mathrm{LZ} \text { CONC }}{(2)}$ & $\frac{\text { RDANCE }}{(3)}$ & $(4)$ & \\
\hline $\log ($ patent stock, $t-1)$ & $0.363^{*}$ & $0.359^{*}$ & $0.262^{*}$ & 0.235 & 0.249 \\
\hline & $(0.190)$ & $(0.189)$ & $(0.156)$ & $(0.149)$ & $(0.152)$ \\
\hline $\log ($ average wage, $t-1)$ & $0.236 * * *$ & $0.218 * * *$ & $0.252^{* * *}$ & $0.247 * * *$ & $0.240 * * *$ \\
\hline \multirow{2}{*}{$\log (L, t-1)$} & $0.529 * * *$ & $0.535 * * *$ & $\begin{array}{l}(0.0281) \\
0.521 * * *\end{array}$ & $\begin{array}{l}(0.02866) \\
0.512^{* * *}\end{array}$ & $\begin{array}{l}(0.0408) \\
0.509 * * *\end{array}$ \\
\hline & $(0.0422)$ & $(0.0422)$ & $(0.0413)$ & $(0.0381)$ & $(0.0338)$ \\
\hline Share big firms, $t-1$ & $1.198^{* *}$ & $1.201 * *$ & $1.025^{* *}$ & $1.009 * *$ & $1.050 * *$ \\
\hline Within env tax, t- 1 & $(0.460)$ & $\begin{array}{c}(0.464) \\
0.00964 \\
(0.00914)\end{array}$ & $(0.449)$ & $(0.469)$ & $\begin{array}{l}0.000110 \\
(0.0127)\end{array}$ \\
\hline \multicolumn{2}{|l|}{ Upstream env tax, $\mathrm{t}-1$} & & $\begin{array}{l}0.104 * * \\
(0.0520)\end{array}$ & & $\begin{array}{c}-0.0838^{* * *} * \\
(0.0256)\end{array}$ \\
\hline \multicolumn{2}{|l|}{ Downstream env tax, $t-1$} & & & $\begin{array}{l}0.165^{* *} \\
(0.0722)\end{array}$ & $\begin{array}{l}0.252^{* * *} * \\
(0.0911)\end{array}$ \\
\hline \multirow{3}{*}{ R sq within $\underset{F}{N}$} & 708 & 708 & 708 & 708 & 708 \\
\hline & 0.217 & 0.217 & 0.226 & 0.234 & 0.235 \\
\hline & 7837.0 & 1965.8 & 2686.8 & 4983.1 & 234.7 \\
\hline \multicolumn{6}{|c|}{ PANEL B - ES CONCORDANCE } \\
\hline Dep: $\log ($ patent_ES, t $)$ & (1) & (2) & (3) & (4) & (5) \\
\hline $\log ($ patent stock, t-1) & $\begin{array}{c}0.524^{* * *} \\
(0.120)\end{array}$ & $\begin{array}{c}0.524^{* * *} \\
(0.120)\end{array}$ & $\begin{array}{c}0.482 * * * \\
(0.117)\end{array}$ & $\begin{array}{c}0.480 * * * \\
(0.114)\end{array}$ & $\begin{array}{c}0.479 * * * \\
(0.116)\end{array}$ \\
\hline $\log ($ average wage, $t-1)$ & $\begin{array}{l}0.0536 \\
(0.0344)\end{array}$ & $\begin{array}{c}0.0539 \\
(0.0433)\end{array}$ & $\begin{array}{l}0.0605 * * \\
(0.0287)\end{array}$ & $\begin{array}{l}0.0574^{*} \\
(0.0310)\end{array}$ & $\begin{array}{l}0.0678^{*} \\
(0.0378)\end{array}$ \\
\hline \multirow[t]{2}{*}{$\log (L, t-1)$} & $0.136^{* * *}$ & $0.136^{* * *}$ & $0.132^{* * *}$ & $0.130^{* * *}$ & $0.127^{* * *}$ \\
\hline & $(0.0200)$ & $(0.0174)$ & $(0.0194)$ & $(0.0191)$ & $(0.0157)$ \\
\hline Share big firms, $t-1$ & 0.285 & 0.285 & 0.212 & 0.220 & 0.212 \\
\hline \multirow[t]{2}{*}{ Within env tax, $t-1$} & & -0.000126 & $(0.362)$ & & -0.00498 \\
\hline & & $(0.00522)$ & & & $(0.00544)$ \\
\hline Upstream env tax, t- 1 & & & $\begin{array}{c}0.0436 * * * \\
(0.0162)\end{array}$ & & $\begin{array}{l}0.00902 \\
(0.0132)\end{array}$ \\
\hline Downstream env tax, $\mathrm{t}-1$ & & & & $\begin{array}{c}0.0567 * * * \\
(0.0212)\end{array}$ & $\begin{array}{l}(0.0132) \\
0.0496^{*} \\
(0.0281)\end{array}$ \\
\hline \multirow{2}{*}{ 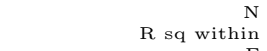 } & 708 & 708 & 708 & 708 & 708 \\
\hline & 0.511 & 0.511 & 0.515 & 0.516 & 0.516 \\
\hline $\mathrm{F}$ & 7056.6 & 1274.7 & 14532.4 & 10949.1 & 77.98 \\
\hline
\end{tabular}


Table 6: TFP and extended production function equations with instrumented patents

\begin{tabular}{|c|c|c|c|c|c|}
\hline \multicolumn{6}{|c|}{ PANEL A - TFP AND LZ CONCORDANCE } \\
\hline Dep. variable: TFP, $t$ & $(1)$ & $(2)$ & $(3)$ & $(4)$ & $(5)$ \\
\hline $\log ($ patent_LZ, t-1) & $\begin{array}{l}0.259^{*} \\
(0.147)\end{array}$ & $\begin{array}{l}0.243^{*} \\
(0.147)\end{array}$ & $\begin{array}{c}0.250 \\
(0.167)\end{array}$ & $\begin{array}{l}0.227 \\
(0.162)\end{array}$ & $\begin{array}{c}0.247 \\
(0.166)\end{array}$ \\
\hline Within env tax, $t-1$ & & $\begin{array}{c}0.0463^{* * *} \\
(0.0115)\end{array}$ & & & $\begin{array}{c}0.0475^{* * * *} \\
(0.0124)\end{array}$ \\
\hline Upstream env tax, $\mathrm{t}-1$ & & & $\begin{array}{l}0.0150 \\
(0.0637)\end{array}$ & & $\begin{array}{c}-0.221 * * \\
(0.100)\end{array}$ \\
\hline Downstream env tax, $\mathrm{t}-1$ & & & & $\begin{array}{c}0.0757 \\
(0.0700) \\
\end{array}$ & $\begin{array}{c}0.286^{* * * *} \\
(0.102)\end{array}$ \\
\hline $\mathrm{N}$ & 708 & 708 & 708 & 708 & 708 \\
\hline $\mathrm{F}$ & 12.29 & 12.57 & 10.80 & 10.96 & 10.46 \\
\hline Test $\mathrm{F}$ of excluded IVs & 16.96 & 16.82 & 15.94 & 16.30 & 15.84 \\
\hline Hansen $\mathrm{J}$ & 2.222 & 2.331 & 2.187 & 1.958 & 1.803 \\
\hline p-value Hansen $\mathrm{J}$ & 0.136 & 0.127 & 0.139 & 0.162 & 0.179 \\
\hline \multicolumn{6}{|c|}{ PANEL B - EXTENDED PRODUCTION FUNCTION AND LZ CONCORDANCE } \\
\hline Dep. variable: $\log (\mathrm{VA}, \mathrm{t})$ & (1) & (2) & $(3)$ & $(4)$ & (5) \\
\hline $\log (\mathrm{L}, \mathrm{t}-1)$ & $0.769 * * *$ & $0.850^{* * *}$ & $0.769^{* * *}$ & $0.768^{* * *}$ & $0.835^{* * *}$ \\
\hline & $(0.130)$ & $(0.128)$ & $(0.129)$ & $(0.131)$ & $(0.122)$ \\
\hline $\log (\mathrm{inv}, \mathrm{t}-1)$ & 0.0377 & 0.0449 & 0.0375 & 0.0357 & $0.0579^{*}$ \\
\hline & $(0.0289)$ & $(0.0290)$ & $(0.0318)$ & $(0.0301)$ & $(0.0306)$ \\
\hline $\log ($ patent_LZ, t-1) & $\begin{array}{c}0.205^{* * *} \\
(0.0731)\end{array}$ & $\begin{array}{l}0.163 * * \\
(0.0693)\end{array}$ & $\begin{array}{c}0.204^{* * *} \\
(0.0741)\end{array}$ & $\begin{array}{l}0.192 * * * \\
(0.0730)\end{array}$ & $\begin{array}{c}0.183^{* * *} \\
(0.0702)\end{array}$ \\
\hline Within env tax, $t-1$ & & $0.0740^{* * *}$ & $(0.0741)$ & $(0.0730)$ & $0.0777^{* * *}$ \\
\hline Upstream env tax, $\mathrm{t}-1$ & & $(0.0134)$ & $\begin{array}{l}0.00126 \\
(0.0388)\end{array}$ & & $\begin{array}{c}(0.0141) \\
-0.147^{* *} \\
(0.0623)\end{array}$ \\
\hline Downstream env tax, $t-1$ & & & & $\begin{array}{c}0.0303 \\
(0.0385) \\
\end{array}$ & $\begin{array}{l}0.148^{* *} \\
(0.0605) \\
\end{array}$ \\
\hline $\mathrm{N}$ & 708 & 708 & 708 & 708 & 708 \\
\hline $\mathrm{F}$ & 18.44 & 22.34 & 18.97 & 18.93 & 20.61 \\
\hline Test $\mathrm{F}$ of excluded IVs & 15.07 & 14.69 & 14.05 & 14.42 & 13.78 \\
\hline Hansen $\mathrm{J}$ & 1.143 & 1.683 & 1.100 & 0.938 & 1.316 \\
\hline p-value Hansen $J$ & 0.285 & 0.194 & 0.294 & 0.333 & 0.251 \\
\hline \multicolumn{6}{|c|}{ PANEL C - TFP AND ES CONCORDANCE } \\
\hline Dep. variable: $\mathrm{TFP}, \mathrm{t}$ & (1) & (2) & (3) & (4) & (5) \\
\hline $\log ($ patent_ES, t-1) & $\begin{array}{c}0.456^{* *} \\
(0.199)\end{array}$ & $\begin{array}{c}0.431 * * \\
(0.198)\end{array}$ & $\begin{array}{c}0.455^{* *} \\
(0.227)\end{array}$ & $\begin{array}{l}0.421 * \\
(0.223)\end{array}$ & $\begin{array}{c}0.443^{* *} \\
(0.225)\end{array}$ \\
\hline Within env tax, $t-1$ & & $\begin{array}{c}0.0469 * * * \\
(0.0116)\end{array}$ & $(0.221)$ & & $\begin{array}{c}0.0493^{* * *} \\
(0.0134)\end{array}$ \\
\hline Upstream env tax, $t-1$ & & & $\begin{array}{l}0.00118 \\
(0.0652)\end{array}$ & & $\begin{array}{r}-0.211 * * \\
(0.0992)\end{array}$ \\
\hline Downstream env tax, $\mathrm{t}-1$ & & & & $\begin{array}{l}0.0555 \\
(0.0742)\end{array}$ & $\begin{array}{l}0.255^{* *} \\
(0.110)\end{array}$ \\
\hline $\mathrm{N}$ & 708 & 708 & 708 & 708 & 708 \\
\hline $\mathrm{F}$ & 12.00 & 12.14 & 10.48 & 10.52 & 9.908 \\
\hline Test $\mathrm{F}$ of excluded IVs & 24.81 & 24.70 & 23.54 & 24.25 & 24.00 \\
\hline Hansen J & 0.000135 & 0.0183 & 0.000243 & 0.00554 & 0.0157 \\
\hline p-value Hansen $J$ & 0.991 & 0.892 & 0.988 & 0.941 & 0.900 \\
\hline \multicolumn{6}{|c|}{ PANEL D - EXTENDED PRODUCTION FUNCTION AND ES CONCORDANCE } \\
\hline Dep. variable: $\log (\mathrm{VA}, \mathrm{t})$ & (1) & (2) & (3) & (4) & (5) \\
\hline $\log (\mathrm{L}, \mathrm{t}-1)$ & $0.794 * * *$ & $0.868^{* * *}$ & $0.794^{* * *}$ & $0.793 * * *$ & $0.861 * * *$ \\
\hline & $(0.129)$ & $(0.126)$ & $(0.128)$ & $(0.130)$ & $(0.122)$ \\
\hline $\log (\mathrm{inv}, \mathrm{t}-1)$ & 0.0287 & 0.0376 & 0.0298 & 0.0280 & 0.0500 \\
\hline & $(0.0290)$ & $(0.0292)$ & & $(0.0297)$ & $(0.0305)$ \\
\hline $\log ($ patent_ES, $t-1)$ & $0.348^{* * *}$ & $0.284 * * *$ & $0.351 * * *$ & $0.337 * * *$ & $0.314^{* * *}$ \\
\hline Within env tax, $t-1$ & $(0.107)$ & $0.0745^{* * *}$ & $(0.109)$ & $(0.111)$ & $0.0791 * * *$ \\
\hline & & $(0.0136)$ & & & $(0.0144)$ \\
\hline Upstream env tax, $\mathrm{t}-1$ & & & -0.00733 & & $\begin{array}{r}-0.137 * * \\
(0.0631)\end{array}$ \\
\hline Downstream env tax, $t-1$ & & & $(0.0404)$ & 0.0159 & $\begin{array}{c}(0.0631) \\
0.124^{*}\end{array}$ \\
\hline & & & & $(0.0415)$ & $(0.0641)$ \\
\hline $\mathrm{N}$ & 708 & 708 & 708 & 708 & 708 \\
\hline $\mathrm{F}$ & 18.68 & 22.45 & 18.83 & 18.65 & 20.03 \\
\hline Test $\mathrm{F}$ of excluded IVs & 21.84 & 21.50 & 20.69 & 21.56 & 21.33 \\
\hline Hansen J & 0.282 & 0.117 & 0.361 & 0.257 & 0.611 \\
\hline p-value Hansen J & 0.596 & 0.732 & 0.548 & 0.612 & 0.434 \\
\hline
\end{tabular}


Table 7: Environmental patents: knowledge production function and productivity equation

\begin{tabular}{|c|c|c|c|c|c|}
\hline \multicolumn{6}{|c|}{ PANEL A - LZ CONCORDANCE } \\
\hline Dependent variable & $\begin{array}{c}(1) \\
\log (\text { env_pat_LZ, t }) \\
\text { FE }\end{array}$ & $\begin{array}{c}(2) \\
\text { TFP,t } \\
\text { FE }\end{array}$ & $\begin{array}{c}(3) \\
\log (\mathrm{VA}, \mathrm{t}) \\
\mathrm{FE}\end{array}$ & $\begin{array}{c}(4) \\
\text { TFP,t } \\
\text { FE-IV }\end{array}$ & $\begin{array}{c}(5) \\
\log (\mathrm{VA}, \mathrm{t}) \\
\text { FE-IV }\end{array}$ \\
\hline Within env tax, $t-1$ & $-0.0124^{* *}$ & $0.0505^{* * *}$ & $0.0814^{* * *}$ & $0.0532 * * *$ & $0.0812^{* * *}$ \\
\hline & $(0.00445)$ & $(0.0119)$ & $(0.0161)$ & $(0.0141)$ & $(0.0139)$ \\
\hline Upstream env tax, $\mathrm{t}-1$ & $\begin{array}{l}-0.204^{* *} \\
(0.0591)\end{array}$ & $\begin{array}{r}-0.199 * * \\
(0.0606)\end{array}$ & $\begin{array}{c}-0.133 * * * \\
(0.0263)\end{array}$ & $\begin{array}{l}-0.157 \\
(0.110)\end{array}$ & $\begin{array}{r}-0.129 * * \\
(0.0637)\end{array}$ \\
\hline Downstream env tax, $t-1$ & $0.304 * *$ & $0.298^{* *}$ & $0.155^{* * *}$ & $0.271^{* *}$ & $0.153^{* * *}$ \\
\hline & $(0.107)$ & $(0.0887)$ & $(0.0267)$ & $(0.113)$ & $(0.0593)$ \\
\hline $\log ($ env_pat_LZ, t-1) & & 0.0570 & $0.0285^{*}$ & $0.585^{* *}$ & 0.0706 \\
\hline $\log (\mathrm{L}, \mathrm{t}-1)$ & $0.213^{*}$ & & $\begin{array}{l}(0.0124) \\
0.930^{* * *}\end{array}$ & & $\begin{array}{l}(0.133) \\
0.909^{* * *}\end{array}$ \\
\hline & $(0.100)$ & & $(0.0776)$ & & $(0.152)$ \\
\hline $\log ($ patent stock, $t-1)$ & 0.138 & & & & \\
\hline $\log ($ average wage, $t-1)$ & $\begin{array}{l}(0.133) \\
-0.0296\end{array}$ & & & & \\
\hline & $(0.0536)$ & & & & \\
\hline Share big firms, t-1 & $\begin{array}{l}1.637 \\
(0.868)\end{array}$ & & & & \\
\hline $\log ($ inv,$t-1)$ & & & $\begin{array}{l}0.0568 * * \\
(0.0171)\end{array}$ & & $\begin{array}{l}0.0564^{*} \\
(0.0296)\end{array}$ \\
\hline & 708 & 708 & 708 & 708 & 708 \\
\hline $\mathrm{R}$ sq within & 0.0929 & 0.141 & 0.417 & & \\
\hline & 4765.7 & 441993.9 & 105.4 & 8.969 & 20.11 \\
\hline Test $\mathrm{F}$ of excluded IVs & & & & 8.585 & 6.327 \\
\hline Hansen J & & & & 1.745 & 2.364 \\
\hline p-value Hansen $J$ & & & & 0.187 & 0.124 \\
\hline \multicolumn{6}{|c|}{ PANEL B - ES CONCORDANCE } \\
\hline Dependent variable & $\underset{\text { FE }}{\log (\text { env_pat_ES, t })}$ & $\begin{array}{c}\text { TFP,t } \\
\text { FE }\end{array}$ & $\underset{\mathrm{FE}}{\log (\mathrm{VA}, \mathrm{t})}$ & $\begin{array}{l}\text { TFP,t } \\
\text { FE-IV }\end{array}$ & $\begin{array}{c}\log (\mathrm{VA}, \mathrm{t}) \\
\text { FE-IV }\end{array}$ \\
\hline Within env tax, t-1 & $-0.0520 * * *$ & $0.0506^{* * *}$ & $0.0818^{* * *}$ & $0.0861 *$ & $0.0912^{* * *}$ \\
\hline Upstream env tax, $\mathrm{t}-1$ & $\begin{array}{l}(0.00807) \\
-0.442 * *\end{array}$ & $\begin{array}{l}(0.0119) \\
-0.203^{* *}\end{array}$ & $\begin{array}{c}(0.0160) \\
-0.136 * * *\end{array}$ & $\begin{array}{l}(0.0479) \\
-0.176\end{array}$ & $\begin{array}{l}(0.0238) \\
-0.132 *\end{array}$ \\
\hline & $(0.120)$ & $(0.0592)$ & $(0.0259)$ & $(0.178)$ & $(0.0782)$ \\
\hline Downstream env tax, $\mathrm{t}-1$ & $0.464^{* * *}$ & $0.301 * *$ & $0.157^{* * *}$ & 0.302 & $0.166^{* *}$ \\
\hline & $(0.131)$ & $(0.0895)$ & $(0.0269)$ & $(0.199)$ & $(0.0803)$ \\
\hline $\log ($ env_pat_ES, t-1) & & 0.0117 & 0.0143 & 1.213 & 0.380 \\
\hline $\log (L, t-1)$ & & $(0.0176)$ & $\begin{array}{l}(0.00993) \\
0.938 * * *\end{array}$ & $(0.988)$ & $\begin{array}{l}(0.417) \\
0.0731^{*}\end{array}$ \\
\hline & $(0.148)$ & & $(0.0833)$ & & $(0.0429)$ \\
\hline $\log ($ patent stock, $t-1)$ & $\begin{array}{l}0.412^{* * *} \\
(0.117)\end{array}$ & & & & \\
\hline $\log ($ average wage, $t-1)$ & -0.133 & & & & \\
\hline & $(0.0761)$ & & & & \\
\hline Share big firms, t-1 & $1.499^{*}$ & & & & \\
\hline $\log (\mathrm{inv}, \mathrm{t}-1)$ & $(0.737)$ & & $\begin{array}{c}0.0576 * * \\
(0.0177)\end{array}$ & & $\begin{array}{c}0.801 * * * \\
(0.193)\end{array}$ \\
\hline & 708 & 708 & 708 & 708 & 708 \\
\hline$R$ sq within & 0.0948 & 0.140 & 0.415 & & \\
\hline & 7470.1 & 850469.8 & 94.10 & 3.790 & 11.83 \\
\hline Test $F$ of excluded IVs & & & & 1.229 & 0.939 \\
\hline Hansen $\mathrm{J}$ & & & & 1.443 & 0.438 \\
\hline p-value Hansen $\mathrm{J}$ & & & & 0.230 & 0.508 \\
\hline
\end{tabular}


Table 8: TFP and extended production function equations with no account for endogeneity of patents

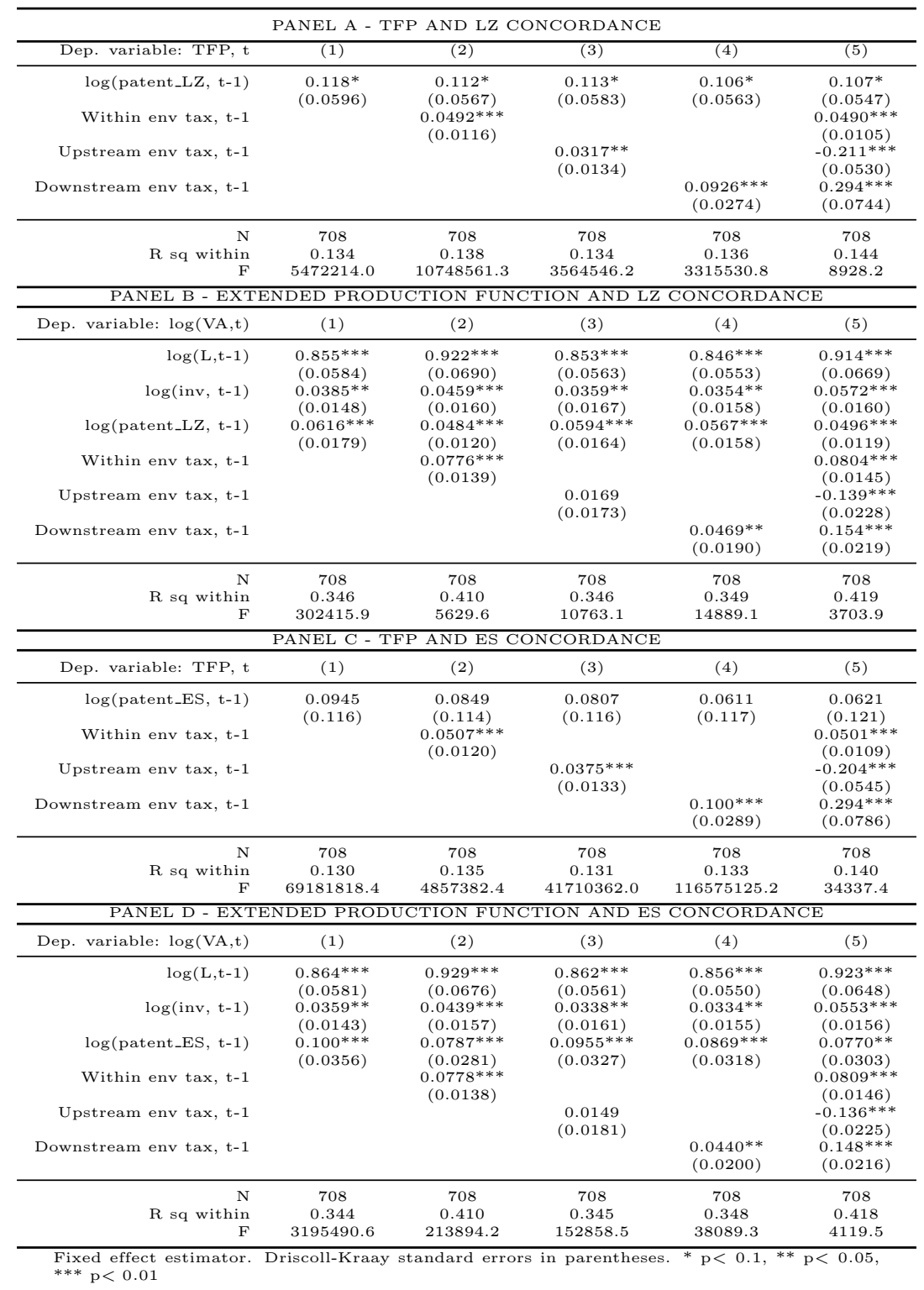

